\title{
A LOCALIZED MAPPED DAMAGE MODEL FOR ORTHOTROPIC MATERIALS
}

\author{
Luca Pelà $^{\mathrm{a} *}$, Miguel Cervera ${ }^{\mathrm{a}}$, Sergio Oller ${ }^{\mathrm{a}}$, Michele Chiumenti ${ }^{\mathrm{a}}$ \\ ${ }^{a}$ CIMNE, Internacional Center for Numerical Method in Engineering, Technical \\ University of Catalonia (UPC), Campus Norte, Jordi Girona 1-3, 08034 Barcelona, \\ Spain.
}

\begin{abstract}
This paper presents an implicit orthotropic model based on the Continuum Damage Mechanics isotropic models. A mapping relationship is established between the behaviour of the anisotropic material and that of an isotropic one. The proposed model is used to simulate the failure loci of common orthotropic materials, such as masonry, fibre-reinforced composites and wood. The damage model is combined with a cracktracking technique to reproduce the propagation of localized cracks in the discrete FE problem. The proposed numerical model is used to simulate the mixed mode fracture in masonry members with different orientations of the brick layers.
\end{abstract}

Keywords: Continuum Damage Mechanics; Orthotropy; Transformation Tensor; Fracture; Crack-tracking; Masonry.

\section{Introduction}

The mechanical behaviour of anisotropic materials involves properties that vary from point to point, due to composite or heterogeneous nature, type and arrangement of constituents, presence of different phases or material defects. A macroscopic continuum model aimed at the phenomenological description of anisotropic materials should account for i) the elastic anisotropy, ii) the strength anisotropy (or yield anisotropy, in case of ductile materials) and iii) the brittleness (or softening) anisotropy [1].

Several materials can be considered, with an acceptable degree of approximation, to be orthotropic, even though some of them are not so in the whole range of behaviour.

\footnotetext{
* Corresponding author: Luca Pelà, Universitat Politècnica de Catalunya - BarcelonaTech, Department of Construction Engineering, C/ Jordi Girona, 1-3 (Module C1 - Office 206-B), 08034 Barcelona - Spain. Phone: +34 934011036 , Fax: +34934054135.

E-mail addresses: luca.pela@upc.edu (Luca Pelà), miguel.cervera@upc.edu (Miguel Cervera), sergio.oller@upc.edu (Sergio Oller), michele@ cimne.upc.edu (Michele Chiumenti).
} 
Modelling the elastic orthotropy does not present big difficulties, since it is possible to use the general elasticity theory [2]. On the other hand, the need to model the strength and nonlinear orthotropic behaviour requires the formulation of adequate constitutive laws, which can be based on such theories as plasticity or damage. In particular, although several failure functions have been proposed, the choice of a suitable orthotropic criterion still remains a complex task.

One of the more popular attempts to formulate orthotropic yield functions for metals in the field of plasticity theory is due to Hill $[3,4]$, who succeeded in extending the von Mises [5] isotropic model to the orthotropic case. The main limitation of this theory is the impossibility of modelling materials that present a behaviour which not only depends on the second invariant of the stress tensor, i.e. the case of geomaterials or composite materials. On the other hand, Hoffman [6] and Tsai-Wu [7] orthotropic yield criteria are useful tools for the failure prediction of composite materials.

For the description of incompressible plastic anisotropy, not only yield functions [8] and phenomenological plastic potentials [9] have been proposed over the years. Other

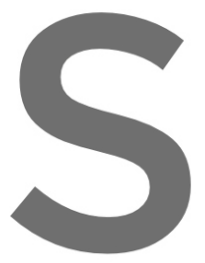
formulation strategies have been developed, related to general transformations based on
theory of tensor representation $[10,11]$. A particular case of this general theory, which is
based on linearly transformed stress components, has received more attention. This
special case is of practical importance because convex formulations can be eastily

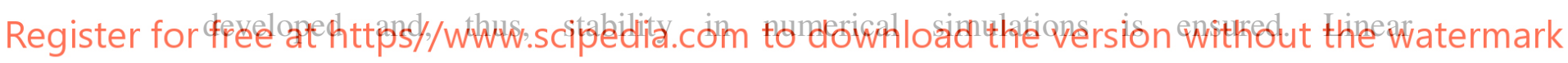
transformations on the stress tensor were first introduced by Sobotka [12] and Boehler and Sawczuck [13]. For plane stress and orthotropic material symmetry, Barlat and Lian [14] combined the principal values of these transformed stress tensors with an isotropic yield function. Barlat et al. [15] applied this method to a full stress state and Karafillis and Boyce [16] generalized it as the so-called isotropic plasticity equivalent theory with a more general yield function and a linear transformation that can accommodate other material symmetries. Betten [17,18] introduced the concept of mapped stress tensor to express the behaviour of an anisotropic material by means of an equivalent isotropic solid (mapped isotropic problem). The same approach was later refined by Oller et al. $[19,20,21,22,23]$ with the definition of transformation tensors to relate the stress and strain tensors of the orthotropic space to those of a mapped space, in which the isotropic criterion is defined. The stress and strain transformation tensors are symmetric and rank-four and establish a one-to-one mapping of the stress/strain components defined in one space into the other and vice versa (Figure 1). The constitutive law and the damage 
criterion are explicitly expressed only in the isotropic mapped space. In this way, it is possible to use standard isotropic models in calculations, with all the related computational benefits, while the information concerning the real orthotropic properties of the material is included in the transformation tensor. The parameters that define the transformation tensor can be calibrated from adequate experimental tests. The implementation of this theory into the framework of the standard FE codes is straightforward.

The aforementioned approach based on mapped tensors was principally addressed to Plasticity problems. Recently it has been extended to Continuum Damage Mechanics (CDM) constitutive laws by Pelà et al. [24,25] and applied to the study of masonry structures. This paper explores the application of the model also to generic orthotropic materials. The underlying theory applied to CDM is recovered and its theoretical consistency and flexibility to different applications are stressed. The proposed mapped damage model is then used to simulate the failure loci of masonry, fibre-reinforced composites and wood.
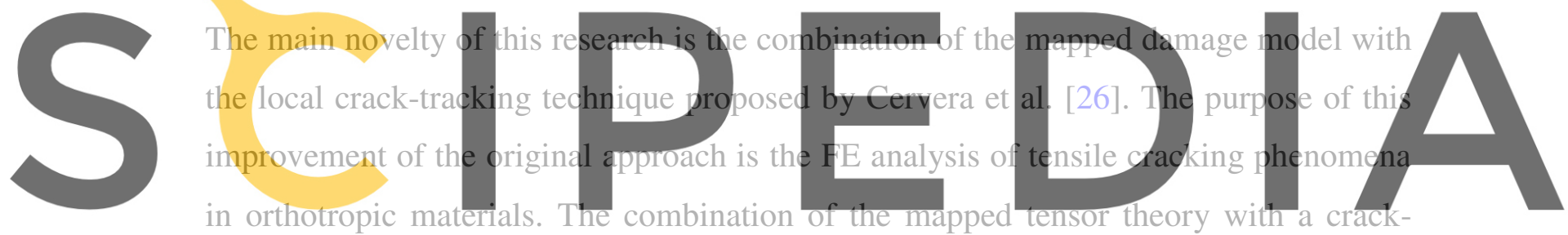

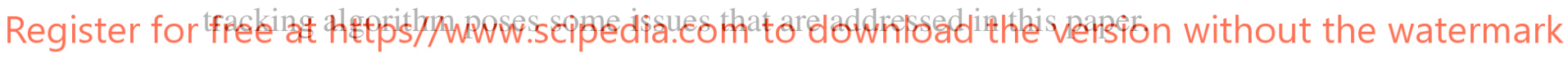
The introduction of local or global crack-tracking techniques into the framework of standard finite elements and constitutive models [25,26] has revealed to be a satisfactory solution to some of the major drawbacks of the classical Smeared Crack Approach (SCA) [27]. In addition to modelling the tensile damage as a smeared quantity spreading over large regions of the FE mesh, the SCA presents other wellknown disadvantages. Firstly, the smeared damage propagation depends on mesh-size and mesh-bias, with a consequent lack of objectivity in the numerical results when different spatial discretizations are considerd. Secondly, crack locking can be observed especially in bending problems, when the advancing flexural crack experiences a sudden "about-turn" [26].

The crack-tracking procedure labels the finite elements which can damage and prevents the others from failing. A correction of spurious changes of crack propagation direction is carried out. These features of the method allow the analyst to avoid the aforementioned problems usually found in classical SCA, without increasing 
excessively the implementation effort or the computational cost. Crack-tracking algorithms are also employed in E-FEM and X-FEM to establish which elements lie in the discontinuity path and need to be enriched [30]. Despite the wide diffusion of the aforementioned procedures, it is worth noting that the introduction of mixed approaches in the field of Computational Failure Mechanics does not require any crack-tracking method $[31,32,33]$.

Benchmark numerical examples are presented to check the capability of the numerical model to reproduce the correct crack paths in a material with different inclinations of the axes of orthotropy. The FE simulation of mixed mode fracture experimental tests on brickwork masonry members is discussed. The model is able to predict the failure load and the cracking path in orthotropic materials subject to complex stress states.

The material is modelled by considering a macro-scale approach and it is represented as a homogeneous continuum. No distinction is made among components if a composite material, e.g. FRP or masonry, is analysed. An alternative treatment is the use of any theory of homogenization $[34,35]$.

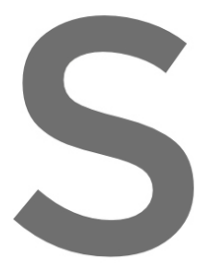

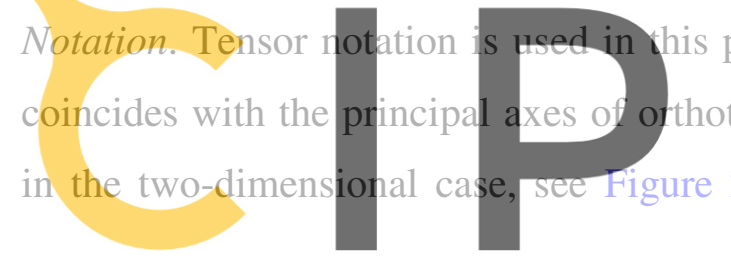

coordinate system are marked by apex

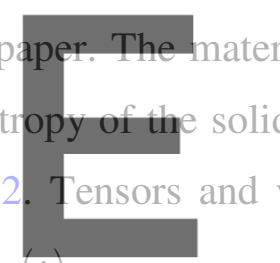

- The angle $\theta$ indicates the inclination

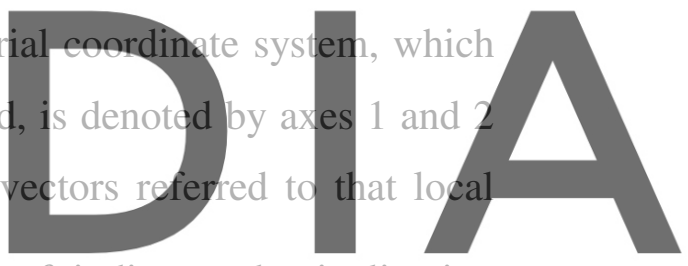

watermark between the material and the global coordinate systems $(x y)$ and it is measured counter

clockwise from the $x$-axis to the 1 -axis. Finally, apex ( $\left.{ }^{*}\right)$ is assigned to variables related to the mapped isotropic space.

\section{Mapped Damage Model}

The orthotropic mapping of CDM constitutive laws has been presented in References $[1,24,25]$. In this section, the basics of the method are recovered and its thermodynamic consistency is demonstrated. The flexibility of the procedure for the application to generic orthotropic materials is stressed.

\subsection{Definition of the Space Transformation Tensors}

The method is based on assuming that the real anisotropic space of stresses $\boldsymbol{\sigma}$ and the conjugate space of strains $\boldsymbol{\varepsilon}$ have their respective image in two mapped isotropic spaces of stresses $\boldsymbol{\sigma}^{*}$ and strains $\boldsymbol{\varepsilon}^{*}$, respectively (Figure 1). The relationship between these spaces is defined by 
$\boldsymbol{\sigma}^{*}=\mathbf{A}^{\boldsymbol{\sigma}}: \boldsymbol{\sigma} \quad$ or $\quad \sigma_{i j}^{*}=A_{i j k l}^{\sigma} \sigma_{k l}$

$\boldsymbol{\varepsilon}^{*}=\mathbf{A}^{\varepsilon}: \boldsymbol{\varepsilon}$ or $\quad \varepsilon_{i j}^{*}=A_{i j k l}^{\varepsilon} \varepsilon_{k l}$

where $\mathbf{A}^{\sigma} \equiv A_{i j k l}^{\sigma}$ and $\mathbf{A}^{\varepsilon} \equiv A_{i j k l}^{\varepsilon}$ are the transformation tensors, for stresses and strains, respectively, relating the mapped and real spaces. These rank four-tensors embody directly the elastic and strength anisotropy of the material. Since the symmetry of the Cauchy stress tensor both in the anisotropic and isotropic spaces is required, it follows that $A_{i j k l}^{\sigma}=A_{j i k l}^{\sigma}=A_{j i l k}^{\sigma}$. The symmetry of the four-rank transformation tensor is also necessary, hence $A_{i j k l}^{\sigma}=A_{k l i j}^{\sigma}$.

The assumption of a strain space transformation tensor [21,22,23], in addition to the definition of the stress space transformation tensor, allows for no-proportionality between the strength and the elastic modulus for each material direction. For this reason, the adopted methodology has been also termed "isotropic mapped model for non-proportional materials" [21]. This feature of the method avoids the basic
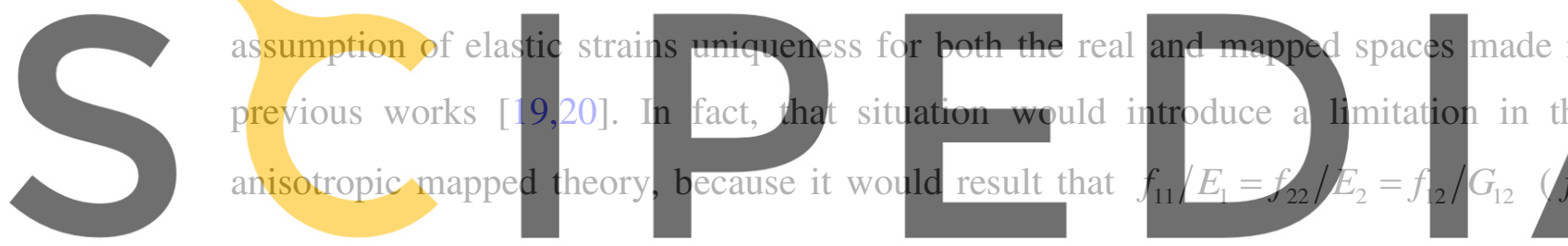

and $E_{i}$ are the uniaxial strengths and the Young's moduli referred to $i$-axes, whereas $f_{i j}$

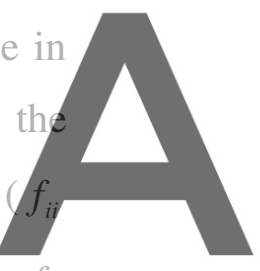

Register for free at https//www.scipedia.com to download the version without the watermark

In this work, the material is assumed to be initially orthotropic and under in-piane stress conditions. There are different alternatives to define the tensor $\mathbf{A}^{\sigma}$ for this case, see for instance Betten [17], Oller et al. [21,22] and Car et al. [36,37]. In this context, the stress space transformation tensor in the material coordinate system (axes 1 and 2, see Figure 2) is:

$$
\begin{aligned}
& A_{1111}^{\sigma}{ }^{\prime}=f_{11}^{*} / f_{11} \\
& A_{2222}^{\sigma}{ }^{\prime}=f_{22}^{*} / f_{22} \\
& A_{1212}^{\sigma}{ }^{\prime}=A_{1221}^{\sigma}{ }^{\prime}=f_{12}^{*} /\left(2 f_{12}\right) \\
& A_{2112}^{\sigma^{\prime}}=A_{2121}^{\sigma^{\prime}}=f_{12}^{*} /\left(2 f_{12}\right) \\
& A_{1122}^{\sigma}{ }^{\prime}=A_{1112}^{\sigma}{ }^{\prime}=A_{1121}^{\sigma}{ }^{\prime}=0 \\
& A_{2211}^{\sigma}{ }^{\prime}=A_{2212}^{\sigma}{ }^{\prime}=A_{2221}^{\sigma}{ }^{\prime}=0 \\
& A_{1211}^{\sigma}{ }^{\prime}=A_{1222}^{\sigma}{ }^{\prime}=A_{2111}^{\sigma}{ }^{\prime}=A_{2122}^{\sigma}{ }^{\prime}=0
\end{aligned}
$$


The orthotropic strengths $f_{i j}$ can be obtained from adequate experimental tests, namely uniaxial tests along directions 1 and 2 and the pure shear test. Assuming an isotropic criterion in the isotropic space, it is $f_{11}^{*}=f_{22}^{*}=f^{*}$. The choice of $f^{*}$ is arbitrary. The expression of $f_{12}^{*}$ depends on the particular isotropic criterion adopted. It is important to note that the procedure may be extended to the 3-dimensional case, at the cost of providing the necessary additional strength parameters.

The stress tensor transformation is sufficient for mapping an explicit isotropic criterion to any implicit orthotropic desired. In fact, carrying out the transformation of stresses is equivalent to mapping the isotropic criterion desired. Any known isotropic criterion can be mapped, such as Tresca, von Mises, Mohr-Coulomb, Drucker-Prager, as well as experimental set of data obtained from laboratory tests. Highly anisotropic surfaces can be represented appropriately by the stress space mapping, such as in the case of fibrereinforced composites [36,37]. The transformation leads to changes in the shape of the failure surface, as shown for instance in Figure 1 for the case of von Mises criterion
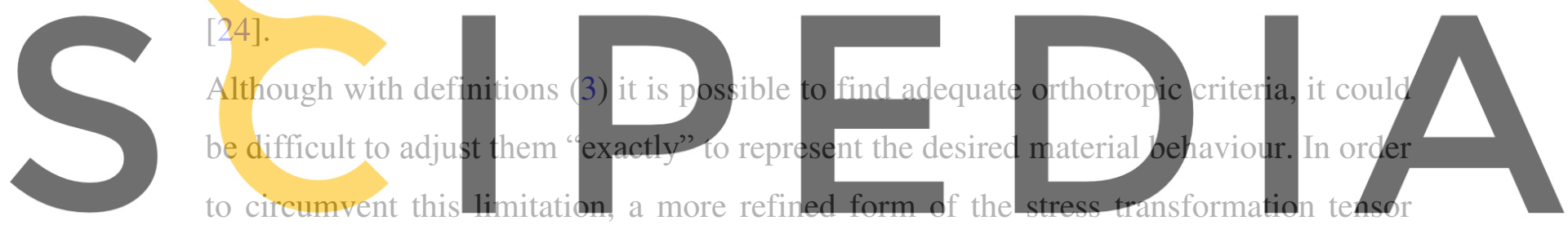

was proposed by Oller et al. [23], making use of a "shape adjustment tensor" whose Register for free at https//www.scipedia.com to download the version without the watermark purpose is to adjust correctly the isotropic criterion to the desired orthotropic one. The

shape adjustment tensor must be derived from a wasteful iterative procedure, since $\mathbf{A}^{\sigma}$ depends on the stress state at each instant of the mechanical process. Although the results obtained by Oller et al. are very accurate, the standard form of the stress transformation tensor will be considered in the present study.

The stress space transformation tensor in the global coordinate system $x_{i}$ is readily obtainable from the definitions (3) of the tensor components in the local principal axes $x_{i}^{\prime}$ of the orthotropic material. If $r_{i j}$ represents $\cos \left(x_{i}^{\prime}, x_{j}\right)$, it results that

$$
A_{i j k l}^{\sigma}=r_{p i} r_{q j} r_{r k} r_{s l} A_{p q r s}^{\sigma}
$$

The tensor $\mathbf{A}^{\sigma}$ must be non-singular, in order to ensure the reversibility of the stress transformation from one space to the other. For this aim, the strength values cannot be equal to zero either in the mapped or in the real space, see Equations (3). Moreover, 
assuming that $f_{i j}^{*}$ have the same sign of $f_{i j}$, the components of $\mathbf{A}^{\boldsymbol{\sigma}^{\prime}}$ are all positive and, therefore, tensor $\mathbf{A}^{\sigma}$ results always positive-definite, in view of (4).

The strain space transformation tensor $\mathbf{A}^{\varepsilon}$ defined in (2) can be derived from (1) and the constitutive equation:

$$
A_{r s m n}^{\varepsilon}=\left(C^{*-1}\right)_{r s i j} A_{i j k l}^{\sigma} C_{k l m n}
$$

where $\mathbf{C}$ and $\mathbf{C}^{*}$ are the constitutive tensors in the real and isotropic space, respectively. It is worth noting that the isotropic solid properties, i.e. $f^{*}$ and elastic constants in tensor $\mathbf{C}^{*}$, can be selected arbitrarily, since they disappear at the end of the mapping procedure to the isotropic space and back to the real one.

\subsection{Underlying Damage Model}

The isotropic CDM constitutive model considered in the mapped space considers one scalar internal variable to monitor the local damage $[38,39,40,41]$. This simple
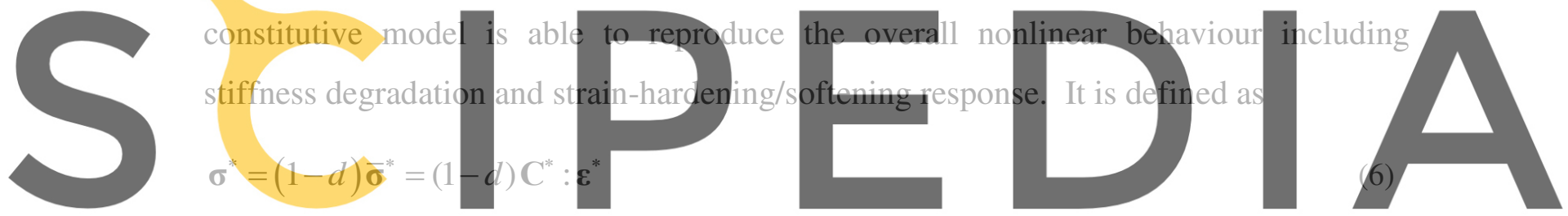

Register for tree at hit the / lamage index $\bar{\sigma}^{*}$ is the offective stress tensor defined under the the

hypothesis of strain equivalence [42] and $\mathbf{C}^{*}$ is a (fourth-order) isotropic linear-elastic

constitutive tensor.

One of the basic ingredients of the underlying damage model is the isotropic criterion, defined as follows

$\Phi^{*}\left(\tau^{*}, r^{*}\right)=\tau^{*}-r^{*} \leq 0$

The variable $r^{*}$ is an internal stress-like variable representing the current damage threshold, as its value controls the size of the (monotonically) expanding damage surface. Its initial value is $r_{0}^{*}=r_{0}^{*}\left(f^{*}\right)$. The equivalent stress $\tau^{*}$ is a positive scalar defined in order to identify "loading", "unloading" or "reloading" situations for a general 3D stress state. It can be expressed in several forms, depending on the damage threshold criterion considered. A general expression, in terms of effective stresses, is [27] 


$$
\tau^{*}=\left[\overline{\boldsymbol{\sigma}}^{*}: \boldsymbol{\Lambda}^{*}: \overline{\boldsymbol{\sigma}}^{*}\right]^{1 / 2}
$$

The shape of the damage threshold surface depends on the particular fourth-order tensor $\Lambda^{*}$ specified.

The constitutive equation for the real orthotropic material is obtained by writing the dissipation occurring in an isothermic elasto-damageable process in the real anisotropic space. The dissipation expression is obtained taking into account the first and second principles of thermodynamics. We define a free potential energy of the following form

$\psi(\boldsymbol{\varepsilon}, r)=[1-d(r)] \psi_{0}=[1-d(r)]\left[\frac{1}{2} \boldsymbol{\varepsilon}: \mathbf{C}: \boldsymbol{\varepsilon}\right] \geq 0$

where $\psi_{0}$ is the elastic free energy potential. All the variables in (9) are amenable to the classical thermodynamic representation [43], i.e. the free variable $\boldsymbol{\varepsilon}$, the internal variable $r$ and the dependent variable $d(r)$.

The second principle of thermodynamics requires the mechanical dissipation to be non-
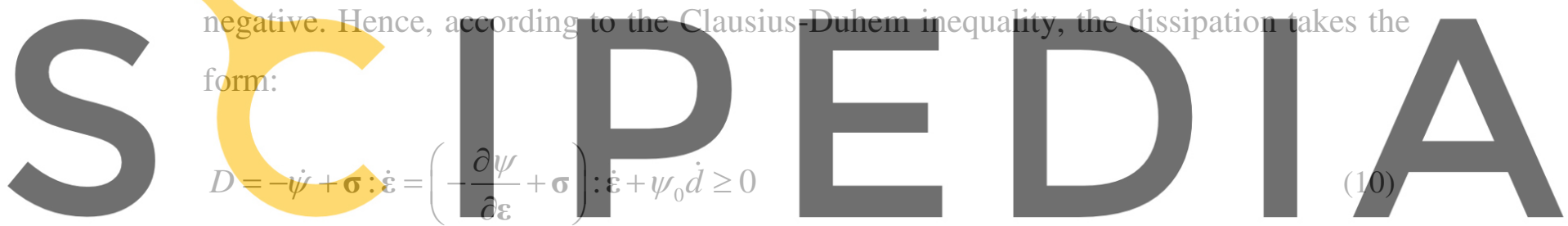

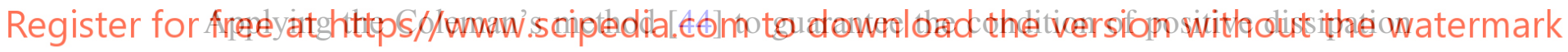

in (10), the constitutive equation for the anisotropic material is obtained finally as

$$
\boldsymbol{\sigma}=\frac{\partial \psi}{\partial \boldsymbol{\varepsilon}}=[1-d(r)] \mathbf{C}: \boldsymbol{\varepsilon}
$$

The expression (9) of the free energy potential can be rewritten by taking into account the relationship between the constitutive tensors in the real and mapped spaces. This gives

$\psi(\boldsymbol{\varepsilon}, r)=\frac{1}{2}[1-d(r)] \boldsymbol{\varepsilon}:\left[\left(\mathbf{A}^{\sigma}\right)^{-1} \cdot \mathbf{C}^{*} \cdot \mathbf{A}^{\varepsilon}\right]: \boldsymbol{\varepsilon}$

The constitutive equation in the real anisotropic space, defined in terms of stress field in the mapped isotropic space, is obtained by substituting (12) into (11), i.e., 


$$
\begin{aligned}
& \boldsymbol{\sigma}=\frac{\partial \psi}{\partial \boldsymbol{\varepsilon}}=[1-d(r)]\left[\left(\mathbf{A}^{\sigma}\right)^{-1} \cdot \mathbf{C}^{*} \cdot \mathbf{A}^{\varepsilon}\right]: \boldsymbol{\varepsilon}= \\
& =[1-d(r)]\left[\left(\mathbf{A}^{\sigma}\right)^{-1} \cdot \mathbf{C}^{*}\right]: \boldsymbol{\varepsilon}^{*}=[1-d(r)]\left(\mathbf{A}^{\sigma}\right)^{-1}: \overline{\boldsymbol{\sigma}}^{*}= \\
& =\left(\mathbf{A}^{\sigma}\right)^{-1}: \boldsymbol{\sigma}^{*}
\end{aligned}
$$

Equation (13) confirms the assumption of space transformations made in (1) and (2).

Finally, it is important to notice that (10) and (11) lead to

$$
D=\psi_{0} \dot{d} \geq 0
$$

i.e. the scalar damage variable increases monotonically.

\subsection{Evolution of the Damage Variable and Inelastic Behaviour}

The damage index $d=d\left(r^{*}\right)$ is explicitly defined in terms of the corresponding current value of the damage threshold, so that it is a monotonically increasing function such that $0 \leq d\left(r^{*}\right) \leq 1$. The evolution of the damage index that has been adopted in this work is

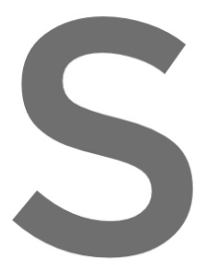
given by the exponential softening lay reported in Ref. [24]. The rate of damage growth
in the nonlinear range is set by the node I fracture energy per unit are $G_{f}^{*}$, that must be
normalized with respect to the finite element characteristic length in order to ensure the FEM solution mesh-independency $[45,46]$. Two different elemental softening

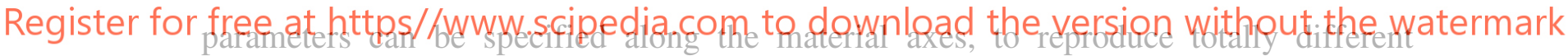
fracture energies along the material directions and provide a full orthotropic softening behaviour.

The capability of the mapped damage model to represent the orthotropic behaviour is demonstrated by considering the following uniaxial tension example. The material properties, referred to the material axes 1 and 2, are the following: Young's moduli $E_{1}=3000 \mathrm{MPa}$ and $E_{2}=2000 \mathrm{MPa}$, Poisson's ratios $v_{12}=0.1$ and $v_{21}=0.15$, shear modulus $G_{12}=900 \mathrm{MPa}$, strength values $f_{11}=0.35 \mathrm{MPa}, f_{22}=0.15 \mathrm{MPa}$ and $f_{12}=0.2 \mathrm{MPa}$, mode I fracture energies $G_{f, l}=100 \mathrm{~J} / \mathrm{m}^{2}$ and $G_{f, 2}=27.6 \mathrm{~J} / \mathrm{m}^{2}$. The values chosen illustrate the fact that different behaviours along the two material axes can be reproduced. The parameters of the 1-direction are selected for the mapped isotropic space.

The case of isotropic softening is considered firstly. Figure 3 a shows the uniaxial tensile stress-strain responses in the $x$-global direction for angles of orthotropy equal to $0^{\circ}, 45^{\circ}$ and $90^{\circ}$. As can be seen, the model is able to capture the stiffness, the strength and the inelastic dissipation in each direction. According to the considered exponential 
softening law, once the fracture energy is exhausted, a no-tension material is recovered. The material strength in the $y$-direction degrades at the same rate of the material strength in the $x$-direction, since material brittleness is the same in all directions.

Figure $3 \mathrm{~b}$ shows the capability of the model to represent the softening orthotropy under uniaxial tension along $x$ - and $y$-global directions. The properties in the real space, referred to the material axes 1 and 2, are the same considered before. In addition to the value of fracture energy in the $y$-direction $G_{f, 2}=27.6 \mathrm{~J} / \mathrm{m}^{2}$, which corresponds to the case of isotropic softening (see [24] for details), other values are considered: $13.8 \mathrm{~J} / \mathrm{m}^{2}$, $41.4 \mathrm{~J} / \mathrm{m}^{2}, 138 \mathrm{~J} / \mathrm{m}^{2}$ and $+\infty$. The assumption of these four values leads to two different softening parameters along the material axes $x$ and $y$. In the first case, the material strength in the $y$-direction degrades at a faster rate than the material strength in the $x$-direction. In the second and third cases, the opposite occurs. The last case represents a hypothetic orthotropic material with a post-peak perfectly plastic behaviour in $y$-direction. Therefore, the proposed model can represent completely different
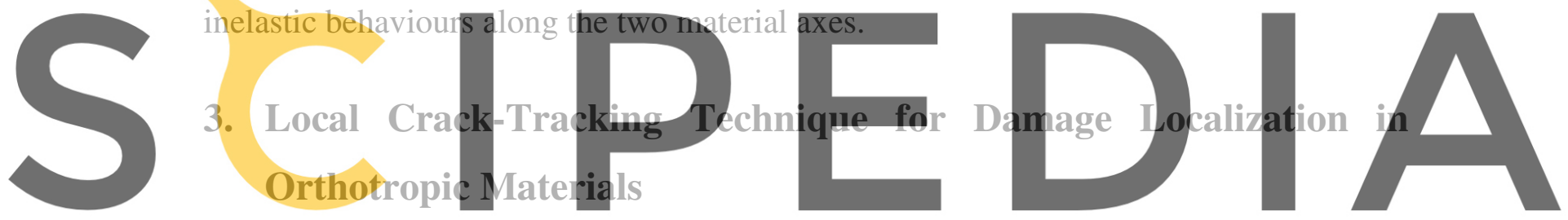

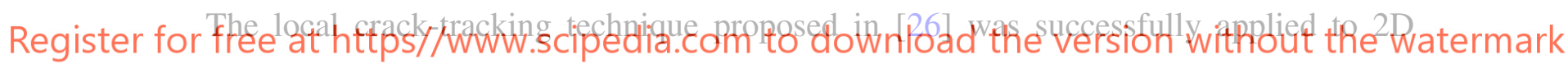
three-noded standard elements with the aim of simulating the propagation of localized cracks in isotropic quasi-brittle materials. The algorithm was validated by comparison with benchmark tests, experimental results and finally used for the pushover analysis of the representative bay structure Mallorca Cathedral [47], showing its usefulness even for large scale structures.

The crack-tracking technique proposed in [26] is extended to orthotropic materials in this work. The method is again based on a flag system that labels the finite elements pertaining to the crack path which may experience damage. The labelling is carried out at every time step during the analysis, prior to the stress computation in finite elements. Instead of assuming an explicit orthotropic cracking criterion with direction dependent strength, a mapped damage model is considered as detailed in Section 2. The isotropic criterion in the mapped space is Rankine and the tensile crack is forced to propagate along a single row of finite elements, according to the direction of the maximum mapped principal tensile stress of each finite element. The crack track is considered 
orthogonal to the first mapped stress eigenvector. The regularization procedure according to the finite element characteristic length mentioned in Section 2.3 ensures that dissipation will be element-size independent.

The crack-tracking algorithm becomes active when there are elements in the FE mesh in which the mapped first principal tensile stress has reached the limit condition according to the Rankine's criterion. Therefore, the detection of crack root elements is carried out in the mapped space. These elements are labelled and can experience damage during the analysis. In case of multi-crack problems, exclusion zones can be defined by the analyst to set a reasonable distance between cracks.

The second step consists in marking the track of finite elements pertaining to the crack path. The criteria used to define the potential damaging elements depend on the magnitude and direction of the mapped principal stresses at each element. The crack propagation direction is computed by considering the direction orthogonal to the corresponding first mapped stress eigenvector of each element. The principal tensile directions of elements, and thus the crack track, are computed in the mapped space, since in this space they are affected by orthotropy by means of the scaling procedure presented in this work. This choice is essential to ensure the correctness of the combination between the mapped damage model and the crack-tracking method, as it will be discussed in Section 4.4.

The procedure uses a flag system to label a) the damaged elements belonging to a crack consolidated in previous steps, b) the potential damaging elements pertaining to the potential crack track and c) the intact elements not able to damage.

A key point of the crack-tracking procedure is the correction of spurious changes of the crack propagation direction. The maximum curvature criterion is adopted [26], consisting in identifying and correcting the sudden change of curvature in the crack track, before marking each potential element. This operation avoids crack locking or abrupt "about-turn" under bending conditions.

\section{Validation Examples}

This section presents the validation of the proposed model by means of comparisons with experimental data of orthotropic materials. Firstly, the orthotropic model is used to reproduce the directional strength of wood, the failure envelopes of composite laminates and masonry. Such applications show how to set the parameters of the model and demonstrate the wide applicability of the method to different orthotropic materials. 
Secondly, the damage model combined with the local crack-tracking technique is used to simulate numerically the cohesive crack propagation in a benchmark uniaxial problem. Finally, the FE analysis of mixed mode fracture experimental tests on brickwork masonry is presented.

\subsection{Directional Strength of Wood}

The uniaxial strength of wood elements is assessed for different orientations of the grain relative to the loading direction. The results from the proposed model are compared with predictions obtained by the common strength criteria generally used for wood.

Hankinson [48] proposed an empirical formula for the determination of the strength of wood. The formula is expressed in terms of the strengths in the axes 1 and 2 (i.e. the grain direction and the perpendicular), the angle $\theta$ between the loading direction and the 1 -axis, and a parameter $n$, which provides information about the shear strength $f_{12}$. On the other hand, Norris [49] developed a theory for the strength of orthotropic materials based on the von Mises [5] theory for isotropic materials. He considered an orthotropic material to be made up of an isotropic material by introducing voids in the shape of equal rectangular prisms. The walls of isotropic material between these voids form the three principal planes of the orthotropic material. Using the energy of distortion expression, he obtained a formula for each of these planes, such as the plane 1-2. Of all the macro-mechanical failure theories for anisotropic materials, the Tsai-Hill [50] theory is the most widely used for wood.

The predictions obtained by the aforementioned criteria for a Sitka spruce (Picea sitchensis) element subjected to tension are compared with the numerical simulations. According to Green [51], typical properties are chosen for this type of wood: $f_{11}=78.3$ $\mathrm{MPa}, f_{22}=2.55 \mathrm{MPa}$ and $f_{12}=7.93 \mathrm{MPa}$. Figure $4 \mathrm{a}$ presents the tensile strength results obtained by assuming $n=1.78$ in the Hankinson formula and taking $f_{12}=6.25 \mathrm{MPa}$ for Norris and Tsai-Hill criteria. These results are compared with those derived by the proposed model, where the von Mises criterion is considered in the mapped isotropic space. The material parameters of the 1-axis have been selected for the mapped isotropic space. As shown, the different approaches lead to very similar results.

Figure $4 \mathrm{~b}$ compares the proposed model with the different theories for the same data, except for $n=1.97$ in the Hankinson formula and $f_{12}=7.93 \mathrm{MPa}$ for Norris and Tsai-Hill criteria. Good agreement is discovered by comparing the proposed model and the other analytical predictions. 


\subsection{Biaxial Failure Envelopes for Unidirectional Fibre-Reinforced Composite Laminae}

Figure 5a shows the comparison of the failure envelope obtained using the proposed model with experimental results [52] for an unidirectional glass fibre reinforced lamina (E-Glass/LY556/HT907/DY063), with a fibre volume fraction $k_{f}=0.62$, under shear stresses and normal stresses orthogonal to fibre direction. Experimental results correspond to tubes of $60 \mathrm{~mm}$ internal diameter and $2 \mathrm{~mm}$ thick. The average properties of the homogenized material are obtained by the information concerning the constituents provided by Soden et al. and the basic formulae of the mixing theory [53]. The experimental data are compared with results derived from the proposed model, in which the Drucker-Prager criterion [54] is considered in the mapped isotropic space. The tension and compression strength values are each the same in the mapped and real spaces and equal $40 \mathrm{MPa}$ and $140 \mathrm{MPa}$, respectively. Real shear strength has been considered equal to $61.2 \mathrm{MPa}$ according to the obtained experimental value. It can be observed that the model reproduces with an acceptable approximation the experimental failure envelope.

Figure $5 \mathrm{~b}$ shows the comparison of failures stresses obtained using the model proposed with experimental ones [52] for a unidirectional carbon fibre-reinforced lamina (T300/BSL914C epoxy), with a fibre volume fraction $k_{f}=0.60$, under shear stresses and normal stresses in the direction of the fibres. Drucker-Prager criterion has been considered in the mapped isotropic space, with $f_{c}^{*}=900 \mathrm{MPa}$ and $f_{t}^{*}=1500 \mathrm{MPa}$. Real shear strength has been defined equal to $101.3 \mathrm{MPa}$ according to the most precise obtained experimental value, see Figure 5b. Good agreement is found between the model prediction and the laminate experimental failure envelope.

\subsection{Uniaxial and Biaxial Failure Envelopes for Masonry}

The ability of the present model to reproduce the orthotropic strength of masonry is assessed through the comparison with experimental data obtained by Page $[55,56]$. Different orientations of the bed joints relative to the loading direction are considered. For each orientation, three different loading patterns were applied, namely uniaxial tension, uniaxial compression and biaxial tension-compression.

For tensile stress states, the Rankine criterion is considered in the mapped isotropic space, whereas the criterion proposed by Faria et al. [57] is considered for compressive stress states. The directional strength characteristics obtained by the proposed model are presented in Figures 6a-c and are compared with the data of Page. Also the results 
obtained by other studies are reported for the sake of argument. Instead of the macromodel considered in this work, Shieh-Beygi and Pietruszczak [58] adopted a mesoscale approach, in which the structural behaviour is examined at the level of constituents, by representing separately bricks and mortar. Kawa et al. [59], on the other hand, make use of a macroscopic failure criterion based on a constrained optimization analysis to assess the orientation of the critical/localization failure plane.

The simulations have been performed for different orientations $\theta$ of the bed joints, namely $0^{\circ}, 22.5^{\circ}, 45^{\circ}, 67.5^{\circ}$ and $90^{\circ}$. The load is gradually increased until the ultimate conditions are reached. The following strength values have been considered for the cases of uniaxial tension and biaxial tension-compression: $f_{11}=0.4 \mathrm{MPa}, f_{22}=0.2 \mathrm{MPa}$ and $f_{12}=0.32 \mathrm{MPa}$. The first value is the mean of the experimental data provided by Page (1983) for $\theta=0^{\circ}$, see Figure $6 \mathrm{a}$. The second strength value has been selected taking into account that, for $\theta=90^{\circ}$, there is a less significant experimental result with a rather pronounced deviation $(\cong 63 \%)$. The shear strength value corresponds to the best fit to Page's experimental curves for the case of tension-compression with $\theta=45^{\circ}$, see Figure 6b. On the other hand, the following strength values have been considered for uniaxial compression: $f_{11}=7.5 \mathrm{MPa}, f_{22}=4.44 \mathrm{MPa}$ and $f_{12}=2.71 \mathrm{MPa}$. The first and the second value are the mean of the experimental data provided by Page for $\theta=0^{\circ}$ and $\theta=90^{\circ}$, see Figure $6 \mathrm{c}$. The shear strength value $f_{12}$ has been selected according to Lourenço [60]. It is worth noting that for all the tests, the material properties in the 1-axis have been selected for the mapped isotropic space. The overall concordance between the trends exhibited by the experimental data and the results obtained by the presented model is remarkable and comparable to those provided by the micro-models.

The set of experimental biaxial compressive strengths given by Page [55] are then considered. The panels were loaded proportionally in the principal stress directions $\sigma_{1}$ and $\sigma_{2}$ along different orientations $\theta$ with respect to the material axes. The criterion proposed by Faria et al. [57] is considered again. The values considered for real strengths are $f_{1}=8.74 \mathrm{MPa}, f_{2}=8.03 \mathrm{MPa}$ and $f_{12}=2.71 \mathrm{MPa}$ according to Lourenço [60], while the parameter $K$ of Faria's criterion has been considered equal to 0.027 in order to fit accurately the experimental data. The material properties in the 1-axis have been selected for the mapped isotropic space. The comparisons between the experimental values and the model are given in Figures 7a-c, corresponding to orientations of the bed joints equal to $0^{\circ}, 22.5^{\circ}$ and $45^{\circ}$, respectively. Globally, good agreement is found. The uniaxial compressive strength parallel to the bed joints seems to be overestimated by the 
model, see Figure 7a, which is due to a debatable definition of failure in the experiments for these loading conditions (early splitting of the bed joints in tension), see Dhanasekar et al. [61]. In fact, the individual "piers" of masonry formed after splitting of the bed joints can withstand a much higher load before collapse is obtained.

\subsection{Holed strip under uniaxial traction}

The proposed localized damage model is validated through the $\mathrm{FE}$ analysis of a benchmark example constituted by a holed strip made of an orthotropic cohesive material.

Calculations are performed with an enhanced version of the FE program COMET [62], developed at the International Center for Numerical Methods in Engineering (CIMNE, Barcelona). The problem is solved incrementally in a (pseudo) time step-by-step manner. Within each step, a modified Newton-Raphson method (using the secant stiffness matrix), together with a line-search procedure, are used to solve the corresponding non-linear system of equations. Convergence of a time step is attained when the ratio between the norm of the iterative residual forces and the norm of the total external forces is lower than 1\%. Pre- and post-processing are done with GiD [63], also developed at CIMNE.

The specimen size is $200 \times 400 \mathrm{~mm}^{2}$ and the perforation is a $14 \times 14 \mathrm{~mm}^{2}$ square. Axial horizontal displacements are applied to both the strip ends. Since the problem is symmetrical, only the right half of the computational domain is considered and discretized with an unstructured mesh with 1903 nodes and 3602 elements with average size of $5 \mathrm{~mm}$. The problem is analysed assuming two-dimensional plane stress conditions.

A fictitious orthotropic material with one weak fracture direction is considered for the strip, with the only aim of verifying the agreement between the crack model and the expected result. The following properties are considered: Young's moduli $E_{1}=E_{2}=30 \mathrm{GPa}$, Poisson's ratios $v_{12}=v_{21}=0$, shear modulus $G_{12}=12.5 \mathrm{GPa}$, strength values $f_{11}=f_{12}=200 \mathrm{MPa}$ and $f_{22}=2 \mathrm{MPa}$, mode I fracture energies $G_{f, l}=2 \mathrm{MJ} / \mathrm{m}^{2}$ and $G_{f, 2}=200 \mathrm{~J} / \mathrm{m}^{2}$. The parameters of the 1-direction are selected for the mapped isotropic space, in which a Rankine criterion is defined.

Figures 8a-b-c-d show the tensile damage contours obtained for angles of orthotropy of $0^{\circ}, 22.5^{\circ}, 45^{\circ}$ and $67.5^{\circ}$. The crack grows from the perforation and then it propagates rightwards following the same inclination of the angle of orthotropy, due to the weak fracture direction in the cohesive material considered. The combination of the 
orthotropic model with the crack-tracking technique can reproduce correctly the expected results.

It is worth emphasizing that the correct crack path can be provided by the FE model only if the crack-tracking procedure is carried out in the scaled (isotropic) mapped space. As discussed in Section 3, the direction of the crack track is assumed orthogonal to the direction of the mapped first principal stress, since the cracking criterion is set in the scaled (isotropic) mapped space $[1,65]$. Note that if the crack-tracking technique was carried out in the real space, the crack paths in the holed strips would result all horizontal for different angles of orthotropy. On the other hand, if the direction of cracks is evaluated by using the mapped isotropic stresses affected by orthotropy via the scaling procedure, the correct crack paths shown in Figures 8a-b-c-d are obtained.

Figure 9 shows the (half)-load vs. (half)-imposed vertical displacement curves obtained by the numerical analyses of strips with different angles of orthotropy. As shown, the model is able to describe correctly the increase of the failure load from the condition in which traction is perpendicular to the weakest fracture plane $\left(\theta=0^{\circ}\right)$ to that in which traction is perpendicular to the strongest material direction and the failure load is very $\operatorname{high}\left(\theta=90^{\circ}\right)$.

\subsection{Mixed mode fracture tests on brickwork masonry beams}

The localized damage model is further validated by simulating numerically mixed mode fracture tests on brickwork masonry under three-point bending configuration with nonsymmetrical boundary conditions (Figure 10).

As in the previous example, calculations are performed with an enhanced version of COMET [62]. The problem is solved in an incremental manner by adopting an arclength algorithm in order to trace the highly nonlinear structural response.

The FE simulations are compared with the experimental tests presented by Reyes et al. [64,65]. Small-scale bricks of $48 \times 24 \times 10 \mathrm{~mm}^{3}$, cut from commercial solid clay bricks, were adopted for the construction of specimens. The mortar used for masonry was composed of Portland cement CEM I $42.5 \mathrm{~N}$ (ASTM Type I), siliceous sand of $1 \mathrm{~mm}$ maximum size, and it is additivated with silica fume (13\% of cement weight) and super plasticiser (3\% of the cement and fume silica weight). Twelve beams with size $675 \times$ $150 \times 26.5 \mathrm{~mm}^{3}$ were built by layering the bricks according to four orientations of the bed joints, i.e. $0^{\circ}, 45^{\circ}, 90^{\circ}$ and $-45^{\circ}$. The specimens were notched in the middle of the span, with a notch to depth ratio of 0.5 . In all cases the tip of the notch was inside a brick unit. Preliminary characterization tests were carried out with the aim of assessing 
the properties of masonry for different orientations of the joints, i.e. $0^{\circ}, 45^{\circ}$ and $90^{\circ}$. The mechanical properties of masonry at the macro scale derived from mode I fracture tests are reported in the following for angles of orthotropy respectively of $0^{\circ}, 45^{\circ}$ and $90^{\circ}$ : Young's modulus 28, 22 and $21 \mathrm{MPa}$, tensile strength 5.8, 4.1 and 2.4 MPa and mode I tensile fracture energy 75,54 and $33 \mathrm{~J} / \mathrm{m}^{2}$.

The results of the preliminary characterization tests are used to calibrate the macro properties of the FE model, in which the composite material is modelled as a homogeneous orthotropic continuum. Accordingly, the Young's moduli and strength values along the horizontal and vertical directions of masonry are $E_{l}=28 \mathrm{GPa}$, $E_{2}=21 \mathrm{GPa}, f_{11}=5.8 \mathrm{MPa}$ and $f_{22}=2.4 \mathrm{MPa}$. Reasonable values for Poisson's ratios $\left(v_{12}=0.2, v_{21}=0.15\right)$ and shear modulus $\left(G_{12}=10 \mathrm{GPa}\right)$ of masonry have been chosen, since they were not provided by the authors. The third strength parameter necessary to map the isotropic Rankine criterion, $f_{12}$, has been calibrated in order to obtain a strength of 4.1 $\mathrm{MPa}$ under uniaxial stress for angle of orthotropy $\theta=45^{\circ}$. After a parametrical analysis the value $f_{12}=6.7 \mathrm{MPa}$ has been used. The orthotropic softening behaviour has been also calibrated making reference to the experimental tests, thus the mode I fracture energies $G_{f, l}=75 \mathrm{~J} / \mathrm{m}^{2}$ and $G_{f, 2}=33 \mathrm{~J} / \mathrm{m}^{2}$ have been chosen. The stress-strain responses to uniaxial tension along different directions of the orthotropic material are shown in Figure 11. As can be seen, the parameters of the proposed damage model have been adjusted properly to the experimental results.

The FE model discretizes the computational domain with an unstructured mesh with 6687 nodes and 13333 elements (Figure 12). The average mesh-size in the zone crossed by the tensile fracture is $h_{\mathrm{e}}=2 \mathrm{~mm}$. The problem is analysed assuming two-dimensional plane stress conditions.

Figure 13 shows the comparison between the experimental crack paths and numerical predictions for different inclinations of the bed joints. The experimental tracks are greatly dependent on the microstructure of the composite material, since they follow the texture of units and the geometry of mortar joints. However, the numerical predictions fit quite well within the experimental envelope and match well the experimental crack patterns.

Figure 14 shows the comparison between the experimental and numerical results in terms of load vs. CMOD for different inclinations of bed joints. The proposed model predicts correctly the variation of peak load with the angle of orientation of brick layers, from the lowest value for $\theta=45^{\circ}$, due to crack propagating along the brick-mortar 
interface, to highest value for $\theta=-45^{\circ}$, due to crack cutting the bricks perpendicularly. Also the dependence of material orthotropy on structural stiffness is well described. The FE model slightly underestimates the experimental values in some cases, e.g. the peak load for $\theta=90^{\circ}$ and the inelastic dissipation for $\theta=0^{\circ}$ and $\theta=-45^{\circ}$. A possible explanation is that the numerical crack paths are shorter than the experimental ones. This is due to the macro-modelling strategy that cannot distinguish units from joints.

\section{Conclusions}

A novel methodology has been presented to simulate numerically the tensile crack propagation in orthotropic materials. An implicit orthotropic damage criterion is formulated by defining an isotropic criterion in a mapped space. Linear transformations for stress and strain tensors from the orthotropic space to the isotropic mapped one are established. The different behaviours along the material axes can be reproduced by means of a very simple formulation, taking advantage of the well-known isotropic damage models. A major advantage lies in the possibility of adjusting an isotropic criterion to the particular behaviour of the orthotropic material. Complex orthotropic damage threshold surfaces can be built by using simpler and well-known isotropic ones, hence avoiding the complex anisotropic yield functions normally adopted in Plasticity. The model can be used for the analysis of different orthotropic materials, such as wood, fibre reinforced composites and masonry.

The mapped damage model is combined with a crack-tracking technique to analyse the fracture of orthotropic materials in the framework of FE method. The numerical tool is suitable for modelling of localized cracking in 2D problems with standard triangular finite elements. The tracking method is able to provide better results than the classical SCA, in terms of mesh-objectivity, numerical robustness and stability. It has been combined carefully with the mapped damage model and validated through the FE analysis of mixed mode fracture tests on masonry members. The results show that the model is able to capture the influence of orthotropy in the structural response, for different inclinations of the brick layers. The numerical results are in a very good agreement with the experimental ones.

The proposed localized damage model is a good compromise between accuracy and simplicity. It requires a low number of input parameters, to be obtained from standard experimental tests. Since the computational costs is limited, it can be used in large scale computations $[47,68,69]$. 


\section{Figures Captions}

Figure 1 Relationship between the mapped isotropic and the real anisotropic spaces (from [24]).

Figure 2 Orthotropic material with material axes of orthotropy 1 and 2.

Figure 3 Stress-strain responses to uniaxial tension for different angles of orthotropy: a) isotropic and b) orthotropic softening.

Figure 4 Comparisons between numerical results and strength values obtained by Hankinson, Norris and Tsai-Hill theories $\left(f_{1}=78.3 \mathrm{MPa}, f_{2}=2.55 \mathrm{MPa}\right)$ : a) $n=1.78$ and $f_{12}=6.25 \mathrm{MPa}$; b) $n=1.97$ and $f_{12}=7.93 \mathrm{MPa}$.

Figure 5 Failure envelopes for unidirectional laminates: a) EGlass/LY556/HT907/DY063; b) T300/BSL914C epoxy.

Figure 6 Failure envelopes at different orientations of the bed joints: uniaxial tension (a), biaxial tension-compression (b) and uniaxial compression (c).

Figure 7 Failure envelopes for biaxial compression-compression: a) $\theta=0^{\circ}$; b) $\theta=22.5^{\circ}$; c) $\theta=45^{\circ}$.

Figure 8 Crack paths for orthotropic holed strip under uniaxial traction: a) $\theta=0^{\circ}$, b) $\theta=22.5^{\circ}$, c) $\theta=45^{\circ}$ and d) $\theta=67.5^{\circ}$.

Figure 9 Load vs. displacement curves for orthotropic holed strips with different angle of orthotropy under uniaxial traction.

Figure 10 Layout and geometry of mixed mode fracture tests carried out by Reyes et al. $[64,65]$.

Figure 11 Stress-strain responses to uniaxial tension along different directions of the orthotropic material considered in the FE macro-model.

Figure 12 FE mesh for the numerical modelling of the test.

Figure 13 Comparison between experimental crack paths (in red) and numerical predictions (in black) for different inclinations of bed joints: a) $\theta=0^{\circ}$, b) $\theta=45^{\circ}$, c) $\theta=90^{\circ}$ and d) $\theta=-45^{\circ}$.

Figure 14 Comparison between experimental and numerical results in terms of load vs. CMOD for different inclinations of bed joints: a) $\theta=0^{\circ}$, b) $\theta=45^{\circ}$, c) $\theta=90^{\circ}$ and d) $\theta=-$ $45^{\circ}$. 


\section{References}

[1] Pelà L. Continuum Damage Model for Nonlinear Analysis of Masonry Structures. Ph.D. thesis, Technical University of Catalonya (UPC), Spain, University of Ferrara, Italy, 2009.

[2] Lekhnitskii SG. Theory of Elasticity of an Anisotropic Body. Holden day, San Francisco, 1963.

[3] Hill R. A Theory of the Yielding and Plastic Flow of Anisotropic Materials. Proceedings of the Royal Society 1948; Series A, 193.

[4] Hill R. The Mathematical Theory of Plasticity. Oxford University Press, London, 1950.

[5] Von Mises R. Mechanics der plastischen Formänderung von Kristallen. Zeitschrift für Angewandte Mathematik Mechanik 1928; 8:161-185.

[6] Hoffman O. The brittle strength of orthotropic materials. Journal of Composite Materials 1967; 1:200-206.

[7] Tsai SW, Wu EM. A general theory of strength for anisotropic materials. Journal of Composite Materials 1971; 5:58-80.

[8] Dutko M, Péric D, Owen DRJ. Universal anisotropic yield criterion based on superquadric functional representation: part 1. Algorithmic issues and accuracy analysis. Computer Methods in Applied Mechanics and Engineering 1993; 109:73-93.

[9] Zyczkowski M. Anisotropic yield conditions. Handbook of Materials Behavior Models, Academic Press, San Diego, 2001, pp. 155-165.

[10] Wang CC. A new representation theorem for isotropic functions, Part I and II. Archive for Rational Mechanics and Analysis 1970; 36:166-223.

[11] Liu SI. On representations of anisotropic invariants. International Journal of Engineering Science 1982; 20:1099-1109.

[12] Sobotka Z. Theorie des plastischen Fliessens von anisotropen Körpern. Zeitschrift für Angewandte Mathematik und Mechanik1969; 49:25-32.

[13] Boehler JP, Sawczuk A. Equilibre limite des sols anisotropes. J. Mécanique 1970; 9:5-33.

[14] Barlat F, Lian J. Plastic Behaviour and Stretchability of Sheet Metals. Part I: a Yield Function for Orthotropic Sheets Under Plane Stress Conditions. International Journal of Plasticity 1989; 5:51-66.

[15] Barlat F, Lege DJ, Brem JC. A Six-Component Yield Function for anisotropic materials. International Journal of Plasticity 1991; 7:693-712. 
[16] Karafillis AP, Boyce MC. A General Anisotropic Yield Criterion using Bounds and a Transformation Weighting Tensor. Journal of the Mechanics and Physics of Solids 1993; 41(12):1859-1886.

[17] Betten J. Creep Theory of Anisotropic Solids. Journal of Rheology 1981; 25(6):565-581.

[18] Betten J. Applications of tensor functions to the formulation of yield criteria for anisotropic materials. International Journal of Plasticity 1988; 4:29-46.

[19] Oller S, Oñate E, Miquel J. Simulation of anisotropic elastic-plastic behaviour of materials by means of an isotropic formulation. In: $2^{\text {nd }} U S$ National Congress on Computational Mechanics, Washington, DC, 1993.

[20] Oller S, Oñate E, Miquel J, Botello S. A finite element model for analysis of multiphase composite materials. In: Ninth International Conference on Composite Materials, Zaragoza, Spain, 1993.

[21] Oller S, Botello S, Miquel J, Oñate E. An anisotropic elastoplastic model based on an isotropic formulation. Engineering Computations 1995; 12(3):245-262.

[22] Oller S, Oñate E, Miquel J. Mixing anisotropic formulation for analysis of composites. Communications in Numerical Methods in Engineering 1996; 12:471-482.

[23] Oller S, Car E, Lubliner J. Definition of a general implicit orthotropic yield criterion. Computer Methods in Applied Mechanics and Engineering 2003; 192:895-912.

[24] Pelà L, Cervera M, Roca P. Continuum damage model for orthotropic materials: application to masonry. Computer Methods in Applied Mechanics and Engineering 2011; 200:917-930.

[25] Pelà L, Cervera M, Roca P. An orthotropic damage model for the analysis of masonry structures. Construction and Building Materials 2013; 41:957-967.

[26] Cervera M, Pelà L, Clemente R, Roca P. A crack-tracking technique for localized damage in quasi-brittle materials. Engineering Fracture Mechanics 2010; 77(13):2431-2450.

[27] Cervera M, Chiumenti M. Mesh objective tensile cracking via a local continuum damage model and a crack tracking technique. Computer Methods in Applied Mechanics and Engineering 2006; 196:304-320.

[28] Cervera M, Chiumenti M. Smeared crack approach: back to the original track. International Journal for Numerical and Analytical Methods in Geomechanics 2006; 30:1173-1199.

[29] Rashid Y. Analysis of prestressed concrete pressure vessels. Nuclear Engineering and Design 1968; 7:334-44. 
[30] Oliver J, Huespe AE, Sánchez PJ. A comparative study on finite elements for capturing strong discontinuities: E-FEM vs. X-FEM. Computer Methods in Applied Mechanics and Engineering 2006; 195:4732-52.

[31] Cervera M, Chiumenti M, Codina R. Mixed stabilized finite element methods in nonlinear solid mechanics. Part I: Formulation. Computer Methods in Applied Mechanics and Engineering 2010; 199:2559-2570.

[32] Cervera M, Chiumenti M, Codina R. Mixed stabilized finite element methods in nonlinear solid mechanics. Part II: Strain localization. Computer Methods in Applied Mechanics and Engineering 2010; 199:2571-2589.

[33] Cervera M, Chiumenti M, Codina R. Mesh objective modeling of cracks using continuous linear strain and displacement interpolations. International Journal of Numerical Methods in Engineering 2011; 87:962-987.

[34] Oller S, Miquel J, Zalamea F. Composite Material Behavior Using a Homogenization Double Scale Method. Journal of Engineering Mechanics 2005; 131(1):65-79.

[35] Quinteros R, Oller S, Nallim L. Nonlinear homogenization techniques to solve masonry structures problems. Composite Structures 2011; 94:724-730.

[36] Car E, Oller S, Oñate E. An anisotropic elastoplastic constitutive model for large strain analysis of fiber reinforced composite materials. Computer Methods in Applied Mechanics and Engineering 2000; 185:245-277.

[37] Car E, Oller S, Oñate E. A large strain plasticity model for anisotropic material composite material application. International Journal of Plasticity 2001; 17:1437-1463.

[38] Simó JC, Ju JW. Strain- and stress-based continuum damage models - I Formulation. International Journal of Solids and Structures 1987; 23:821-840.

[39] Simó JC, Ju JW. Strain- and stress-based continuum damage models - II Computational Aspects. International Journal of Solids and Structures 1987; 23:841-869.

[40] Oliver J, Cervera M, Oller S, Lubliner J. Isotropic Damage Models and Smeared Crack Analysis of Concrete. Proceedings of the $2^{\text {nd }}$ International Conference on Computer Aided, Analysis and Design of Concrete Structures. Austria: Zell am See, 1990, pp. 945-957.

[41] Cervera M. Viscoelasticity and Rate-Dependent Continuum Damage Models. CIMNE, Monography N ${ }^{\circ}-79$, Technical University of Catalunya, Barcelona, Spain, 2003.

[42] Lemaitre J, Chaboche JL. Aspects phénoménologiques de la rupture par endommagement. Journal de Mécanique Appliquée 1978; 2:317-365. 
[43] Lemaitre J, Chaboche JL. Mécanique des matériaux solides. Dunod, Paris, 1985.

[44] Coleman B.D., Gurtin M.E. Thermodynamics with internal state variables. Journal of Chemistry and Physics 1967; 47: 597-613.

[45] Oliver J. A consistent characteristic length for smeared cracking models. International Journal of Numerical Methods in Engineering 1989; 28:461-474.

[46] Bazant ZP, Oh BH. Crack band theory for fracture of concrete. Materials and Structures $1983 ; 16: 155-177$.

[47] Roca P, Cervera M, Pelà L, Clemente R, Chiumenti M. Continuum FE models for the analysis of Mallorca Cathedral. Engineering Structures 2013; 46:653-670.

[48] Hankinson RL. Investigation of Crushing Strength of Spruce at Varying Angles of Grain. Air Service Information Circular No. 259, U.S. Air Service, 1921.

[49] Norris CB. Strength of Orthotropic Materials Subjected to Combined Stresses. U.S. Forest Products Laboratory Rep. 1816, FPL, Madison, Wisconsin, 1955.

[50] Azzi VD, Tsai SW. Anisotropic Strength of Composites. Experimental Mechanics 1965; 5(9): 283-288.

[51] Green DW. Wood: Strength and Stiffness. Encyclopedia of Materials: Science and Technology, Pergamon, 2001, pp. 9732-9736.

[52] Soden PD, Hinton MJ, Kaddour AS. Biaxial test results for strength and deformation of a range of E-glass and carbon fibre reinforced composite laminates: failure exercise benchmark data. Composites Science and Technology 2002; 62:1489-1514.

[53] Daniel IM, Ishai O. Engineering Mechanics of Composites Materials. Oxford University Press, Oxford, 1994.

[54] Drucker DC, Prager W. Solid mechanics and plastic analysis for limit design. Quarterly of Applied Mathematics 1952; 10(2):157-165.

[55] Page AW. The biaxial compressive strength of brick masonry. Proceedings of the Institution of Civil Engineers 1981; 71(2):893-906.

[56] Page AW. The strength of brick masonry under biaxial tension-compression. International Journal of masonry Constructions 1983; 3(1):26-31.

[57] Faria R, Oliver J, Cervera M. A Strain-Based Plastic Viscous-Damage Model for Massive Concrete Structures. International Journal of Solids and Structures 1998; 35(14):1533-1558. 
[58] Shieh-Beygi B, Pietruszczak S. Numerical analysis of structural masonry: mesoscale approach. Computers and Structures 2008; 86:1958-1973.

[59] Kawa M, Pietruszczak S, Shieh-Beygi B. Limit states for brick masonry based on homogenization approach. International Journal of Solids and Structures 2008; 45:998-1016.

[60] Lourenço PB. Computational Strategy for Masonry Structures. Delft University Press, The Netherlands, 1996.

[61] Dhanasekar M, Page AW, Kleeman PW. The failure of brick masonry under biaxial stresses. Proceedings of the Institution of Civil Engineers 1985; 79(2):295-313.

[62] Cervera M, Agelet de Saracibar C, Chiumenti M. COMET: COupled MEchanical and Thermal analysis - data input manual version 5.0. Technical report IT-308. CIMNE, Technical University of Catalonia, 2002.

[63] GiD: the personal pre and post-processor. CIMNE, Technical University of Catalonia, 2002. <http://gid.cimne.upc.es>.

[64] Reyes E, Casati MJ, Gálvez JC. Cohesive crack model for mixed mode fracture of brick masonry. International Journal of Fracture 2008; 151:29-55.

[65] Reyes E, Gálvez JC, Casati MJ, Cendón DA, Sancho JM, Planas J. An embedded cohesive crack model for finite element analysis of brickwork masonry fracture. Engineering Fracture Mechanics 2009; 76:1930-1944.

[68] Roca P, Cervera M, Gariup G, Pelà L. Structural Analysis of Masonry Historical Constructions. Classical and Advanced Approaches. Archives of Computational Methods in Engineering 2010; 17:299-325.

[69] Roca P, Cervera M, Pelà L, Clemente R, Chiumenti M. Viscoelasticity and damage model for creep behaviour of historical masonry structures. The Open Civil Engineering Journal 2012; 6(Suppl. 1-M7):188-199. 


\section{NOMENCLATURE}

$\mathbf{A}^{\sigma}$

$\mathbf{A}^{\varepsilon}$

C

$d$

D

$E_{i}$

$f_{i i}$

$f_{i j}$

$G_{f, i}$

$G_{i j}$

$k_{f}$

K

$n$

$r$

$r_{i j}$

$x_{i}$

$\varepsilon$

$\theta$

$\Lambda$

$v_{i j}$

$\sigma_{i}$

$\boldsymbol{\sigma}$

$\overline{\boldsymbol{\sigma}}$

$\tau$

$\Phi$

$\psi$

$\psi_{0}$

Stress transformation tensor

Strain transformation tensor

Linear-elastic constitutive tensor

Damage index

Specific dissipated energy

Young's modulus referred to $i$-axes

$f_{i i} \quad$ Uniaxial strength in the i-th direction

Pure shear strength in the ij-th plane

Mode I fracture energy per unit area along the i-th direction

Shear modulus in the $\mathrm{ij}$-th plane

Fibre volume fraction

Parameter of Faria's criterion

Parameter of Hankinson's formula

Damage threshold internal variable

Direction cosines

Coordinate system

Strain tensor

Angle of orthotropy

Damage threshold surface shape tensor

Poisson's ratio in the ij-th plane

i-th principal stress

Stress tensor

Effective stress tensor

Equivalent stress

Damage criterion function

Free energy potential

$\quad$ Elastic free energy potential

Double contraction

Apex denoting vectors/tensors defined in the principal axes of orthotropy Apex assigned to scalars/tensors defined in the mapped space 


\section{ACRONYMS}

CDM Continuum Damage Mechanics

CMOD Crack Mouth Opening Displacement

E-FEM Elemental enrichment Finite Element Method

FE

Finite Element

FEM Finite Element Method

FRP Fiber Reinforced Polymer

SCA Smeared Crack Approach

X-FEM eXtended Finite Element Method

$2 \mathrm{D}$

Two-dimensional 


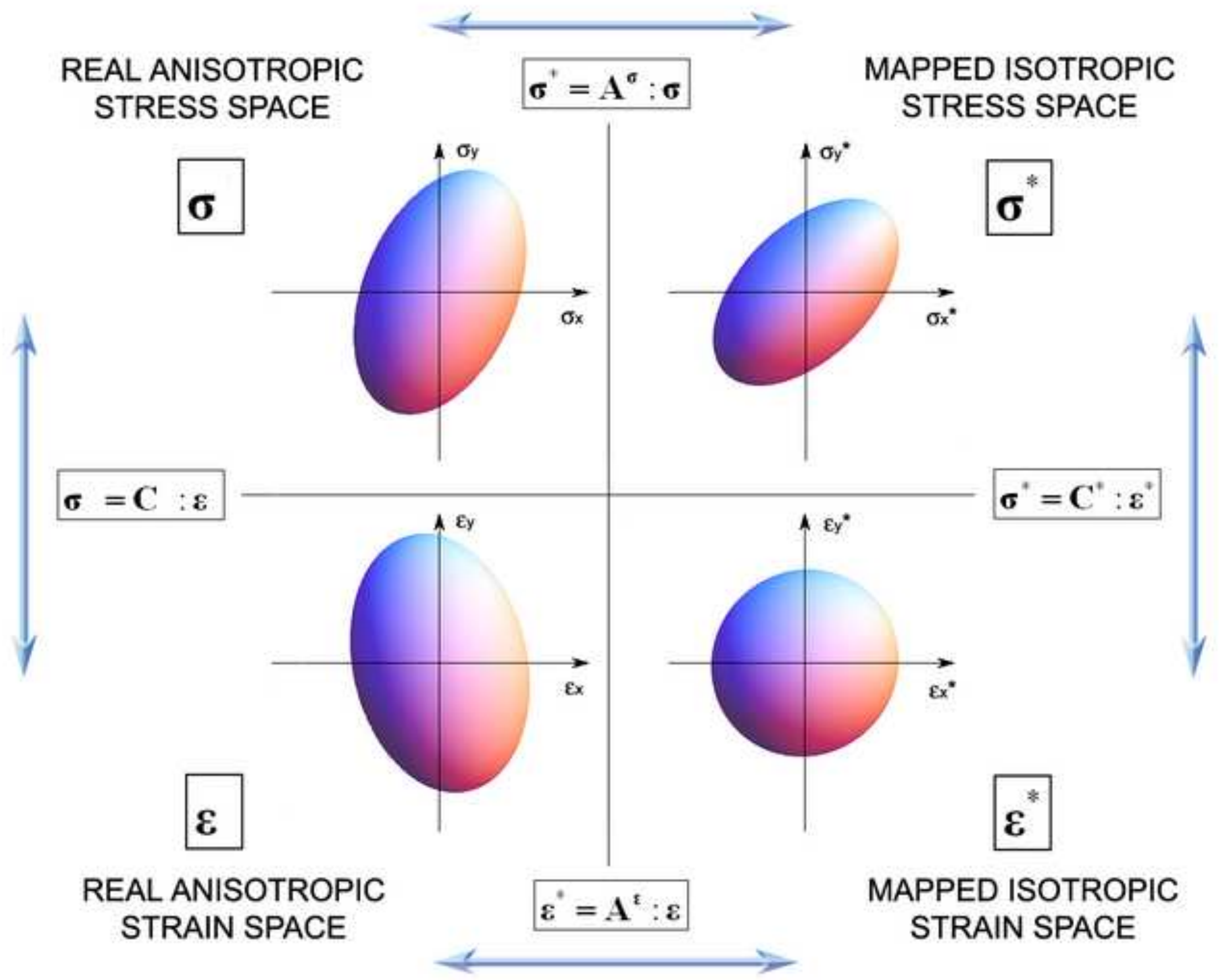


Click here to download high resolution image

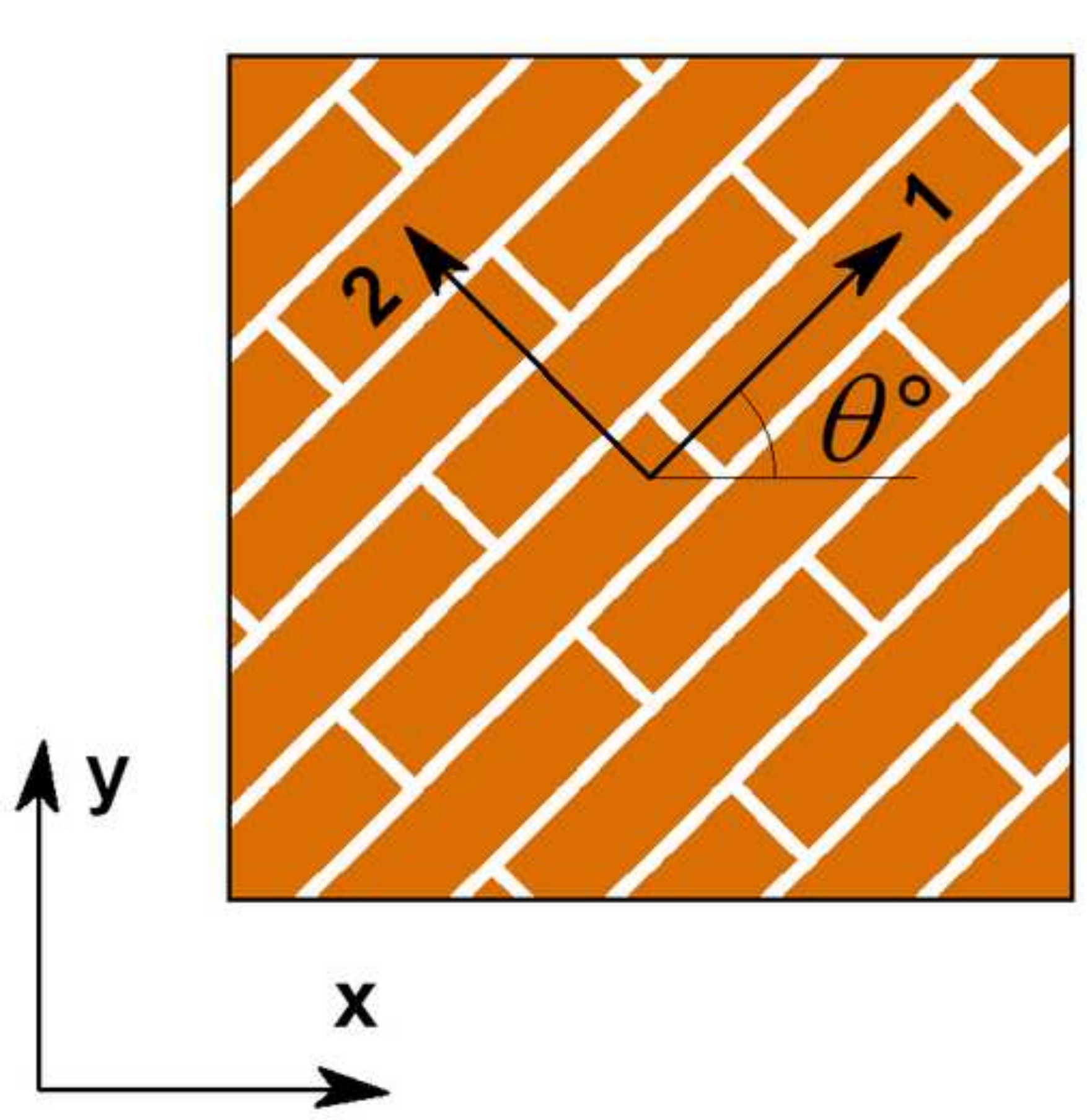



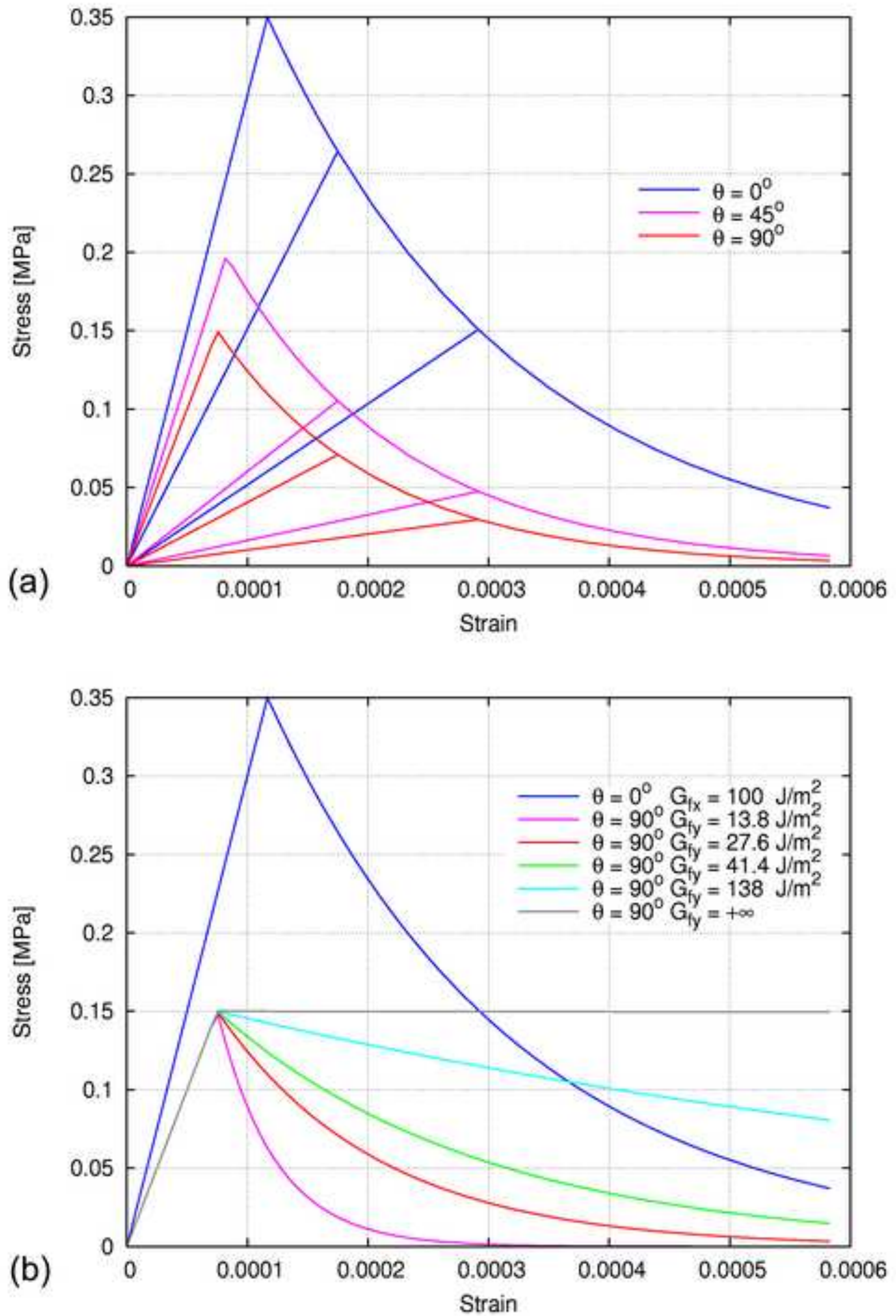

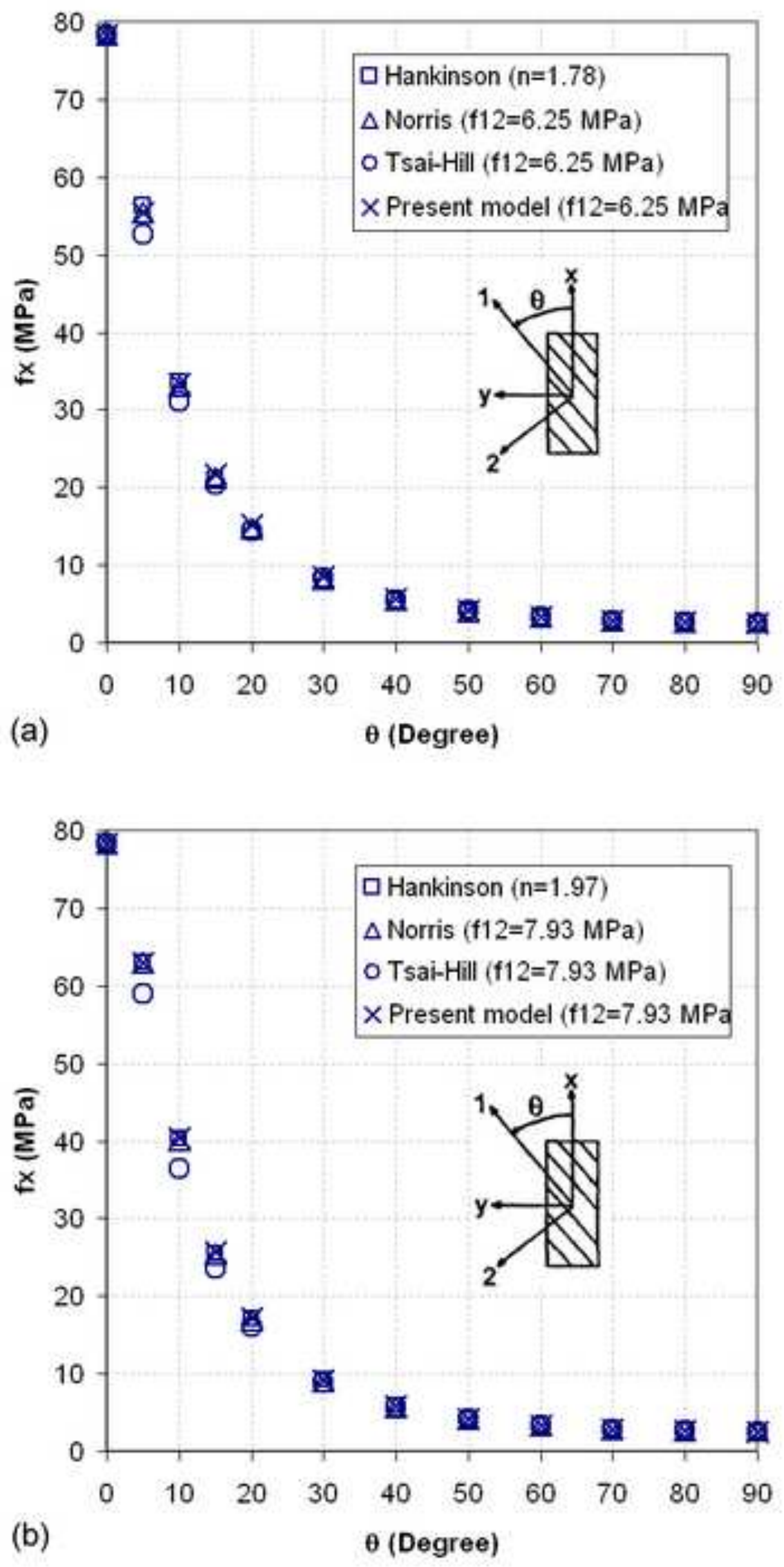


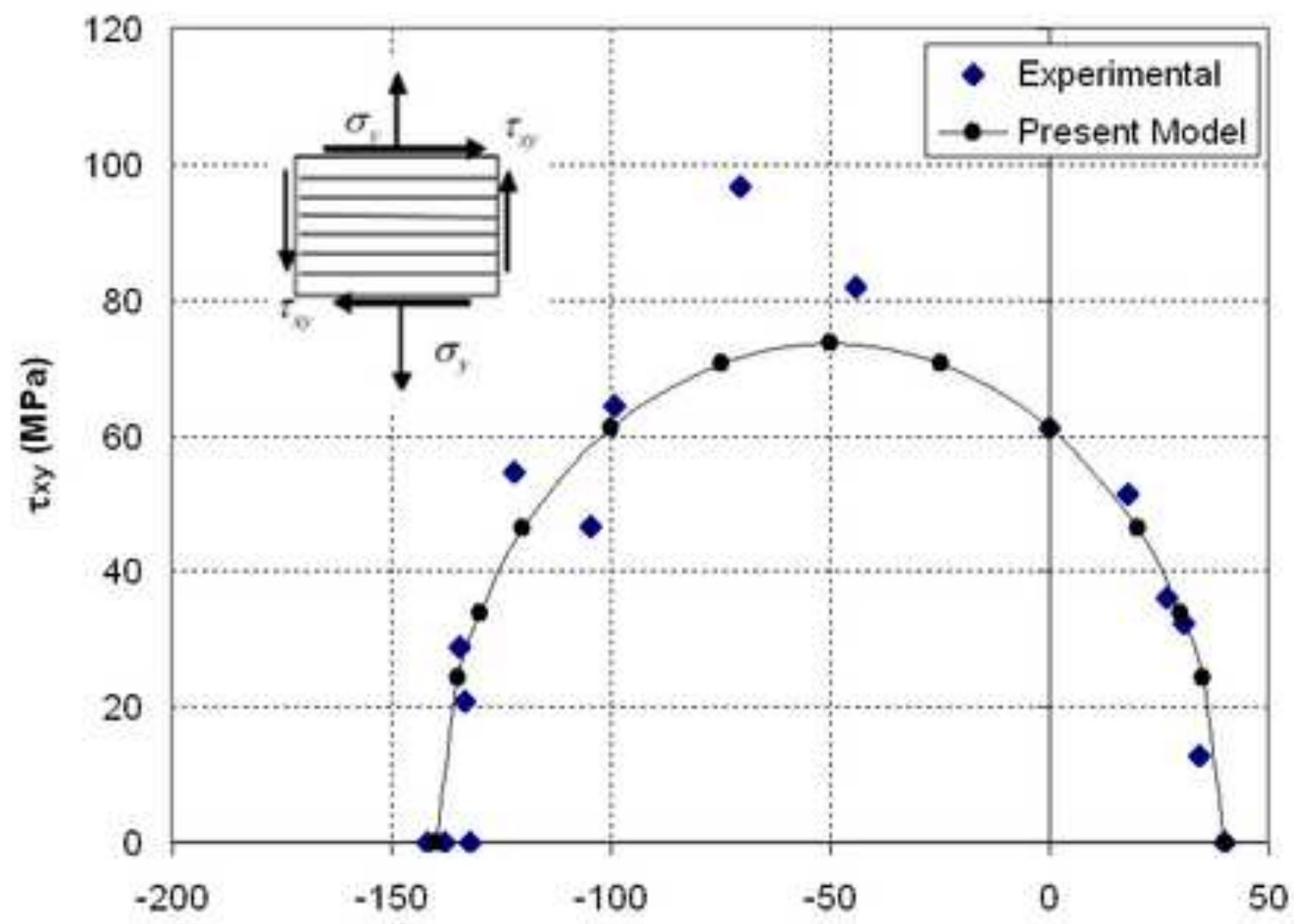

(a)

$$
\sigma_{\mathrm{y}}(\mathrm{MPa})
$$

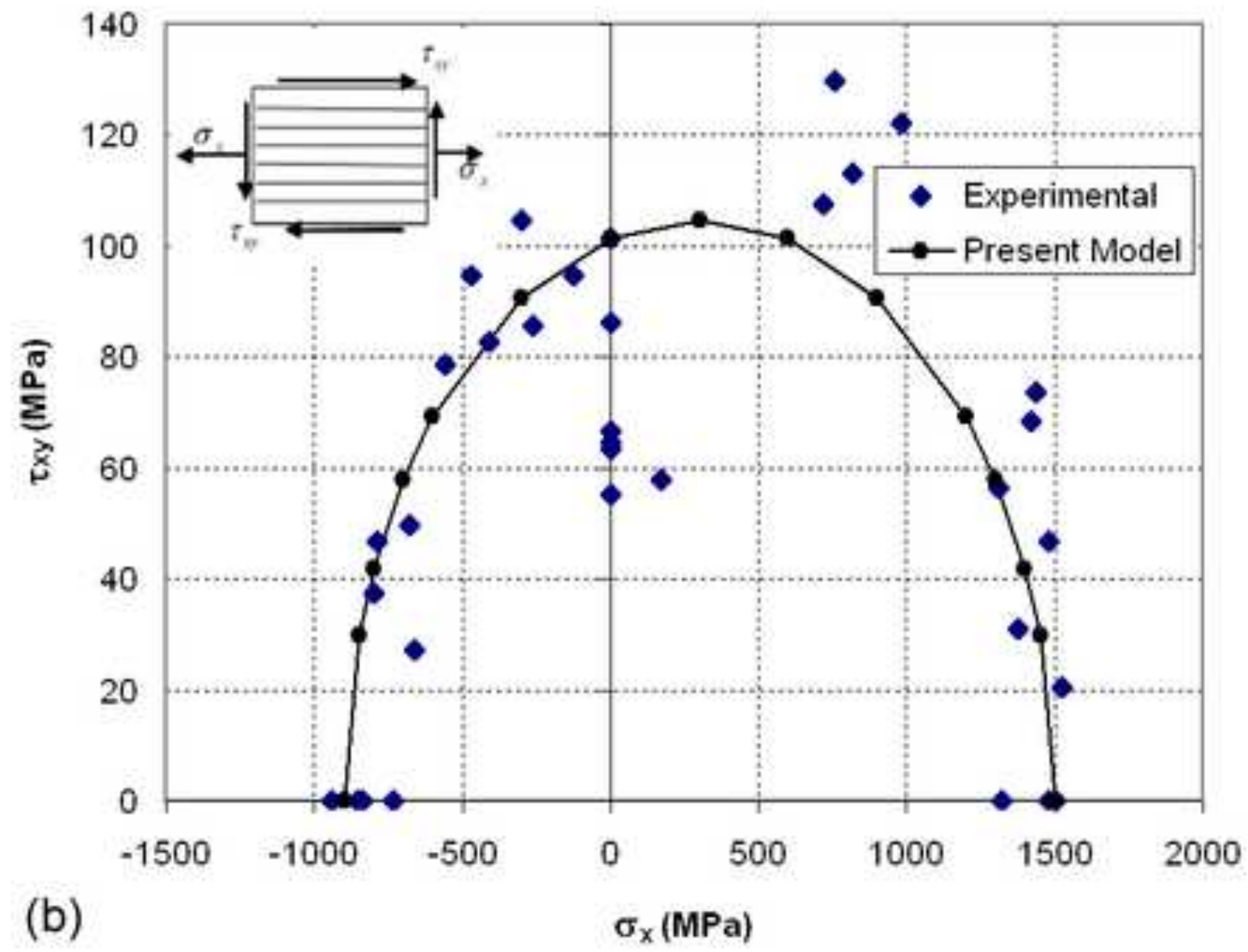




\section{Click here to download high resolution image}
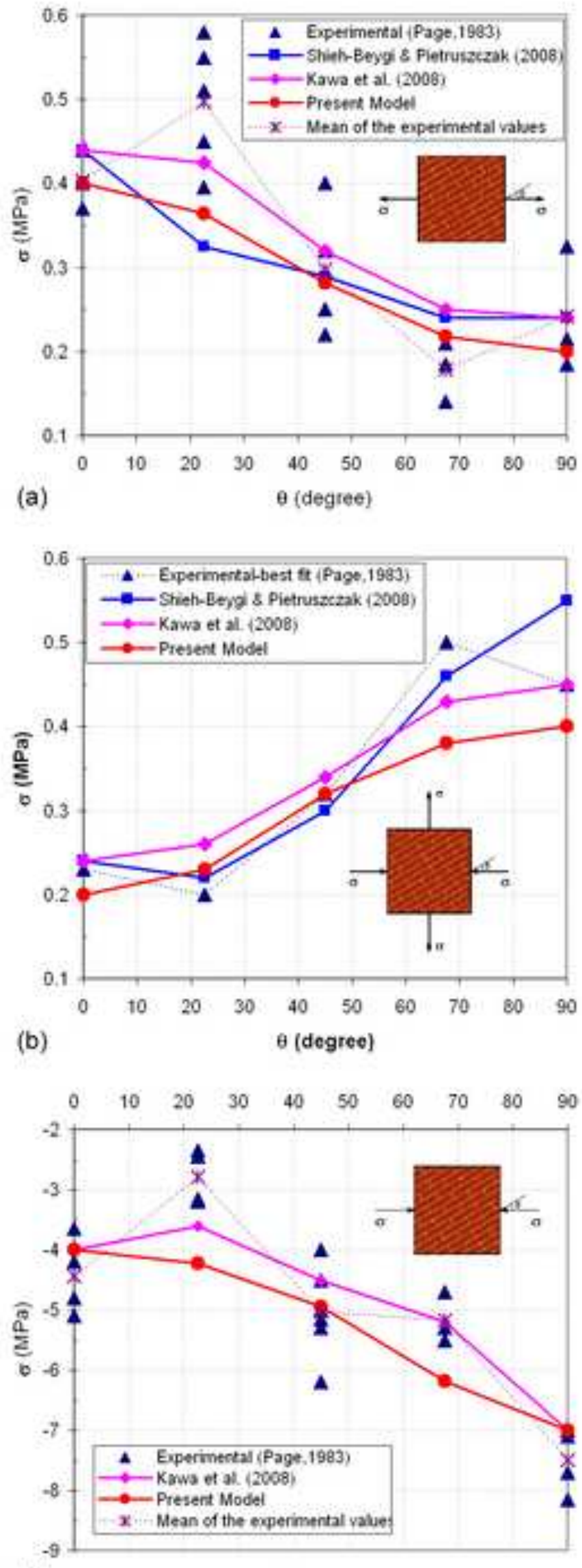

(c)

0 (degree)

$$
0 \text { (degree) }
$$




\section{Figure 7}

Click here to download high resolution image

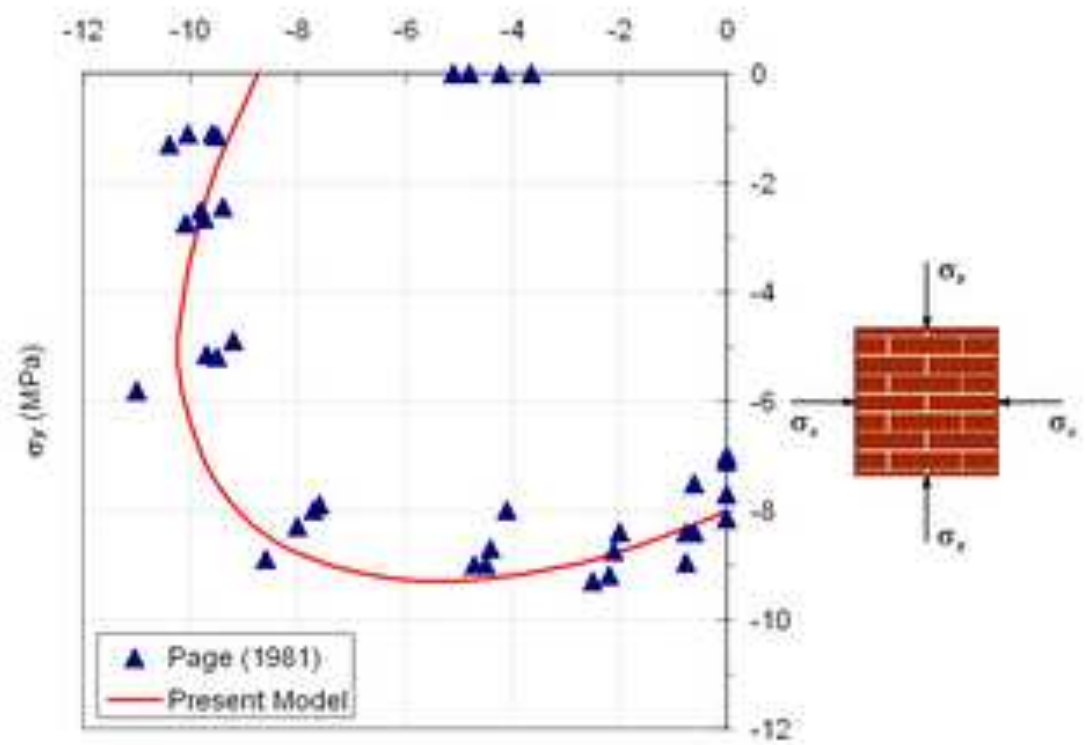

(a)

a, (MPa)

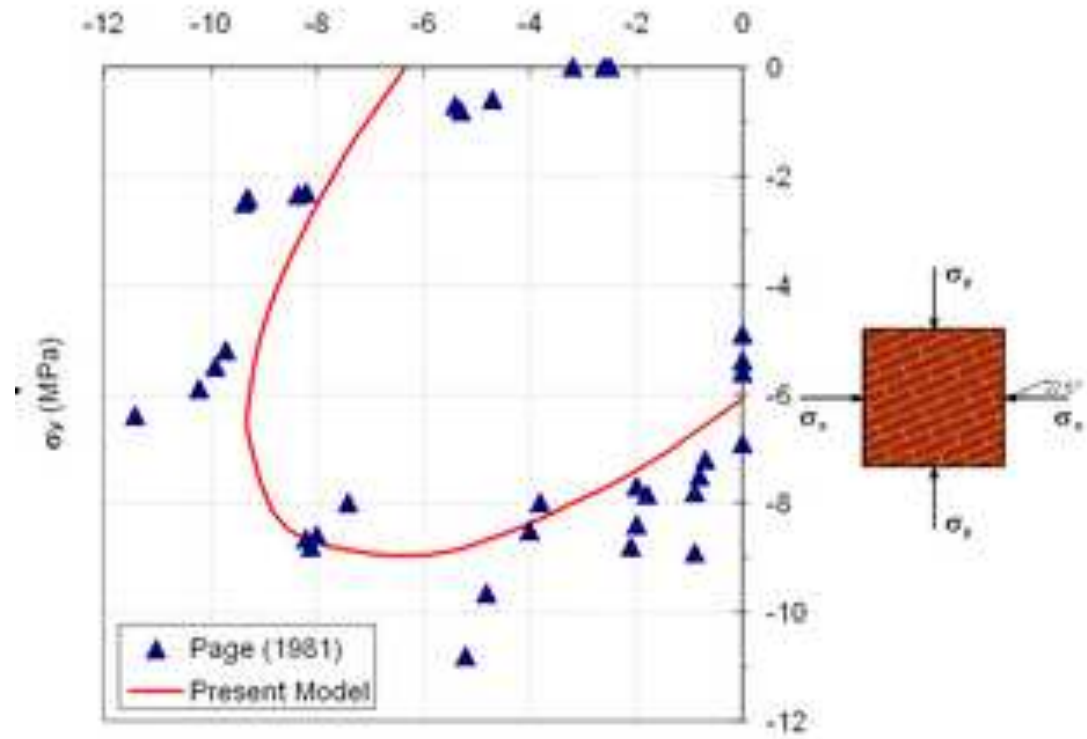

(b) $\quad \sigma_{2}(M P a)$

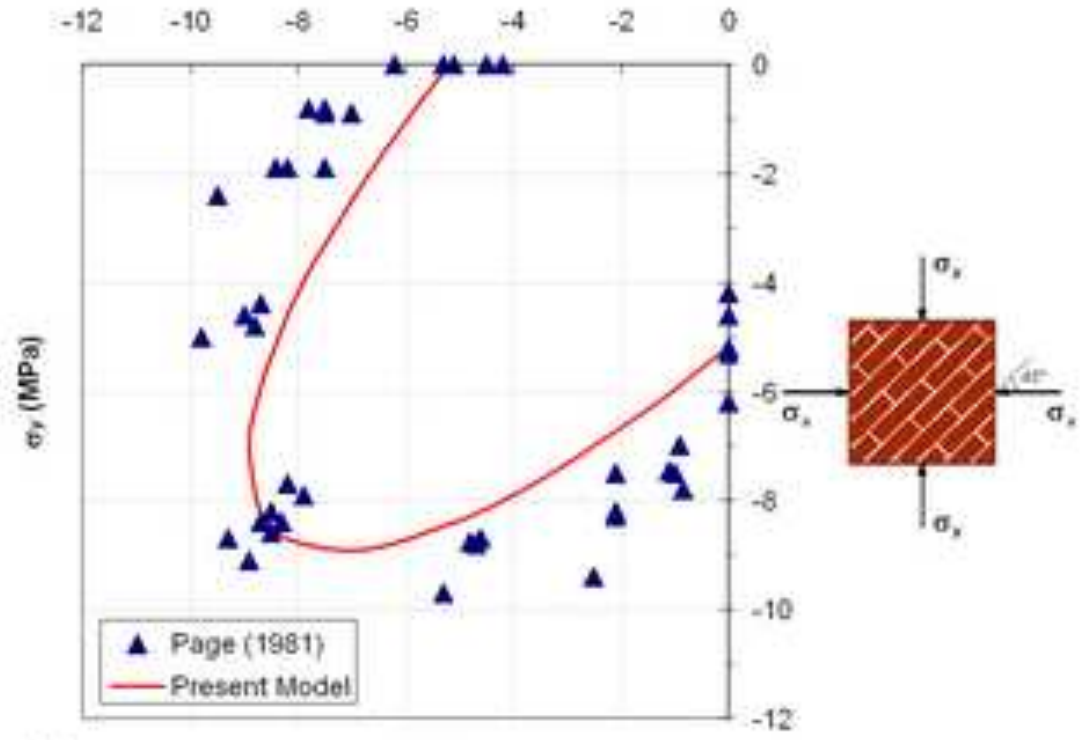

(c)

$\sigma_{x}$ (MPa) 

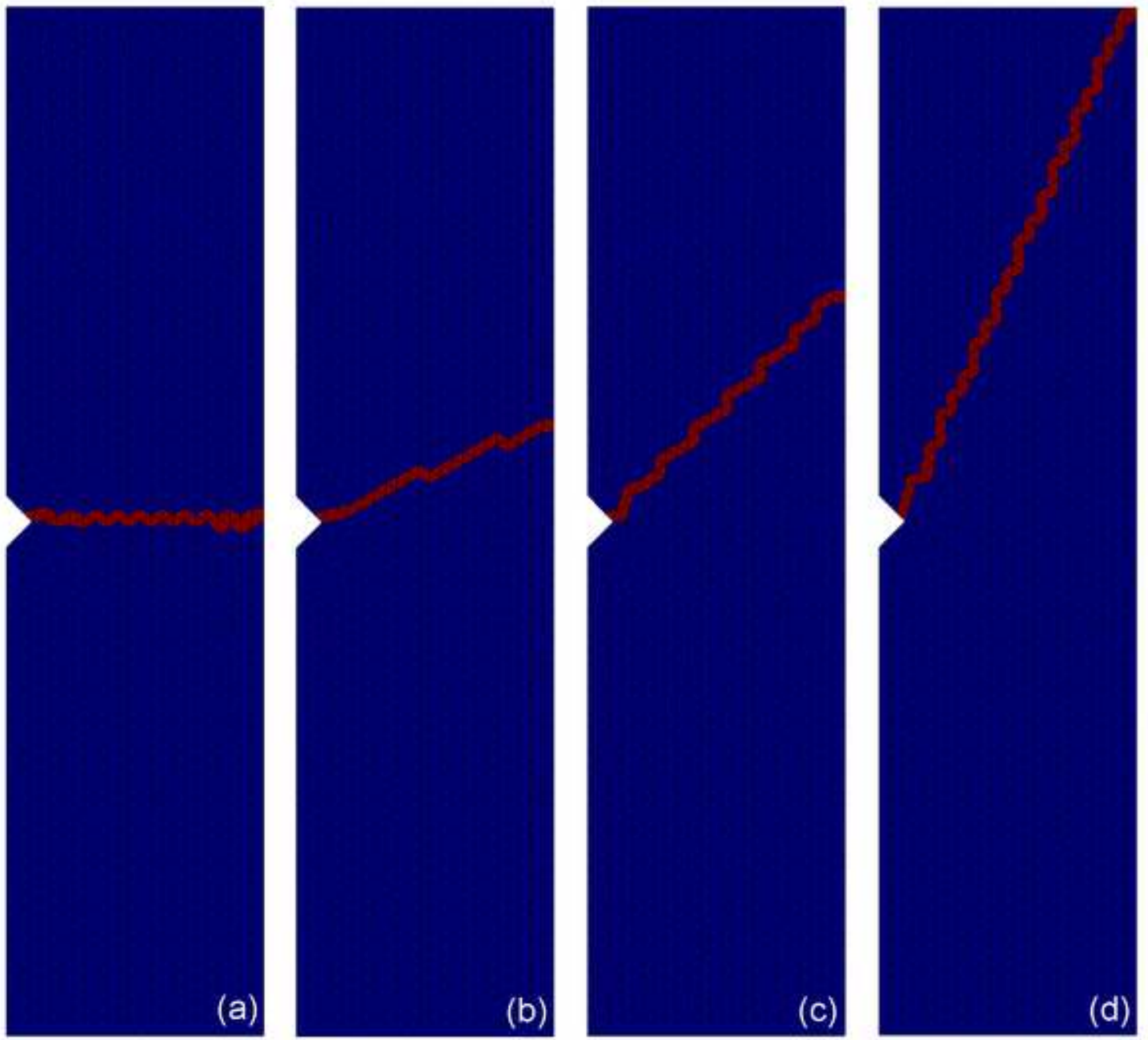


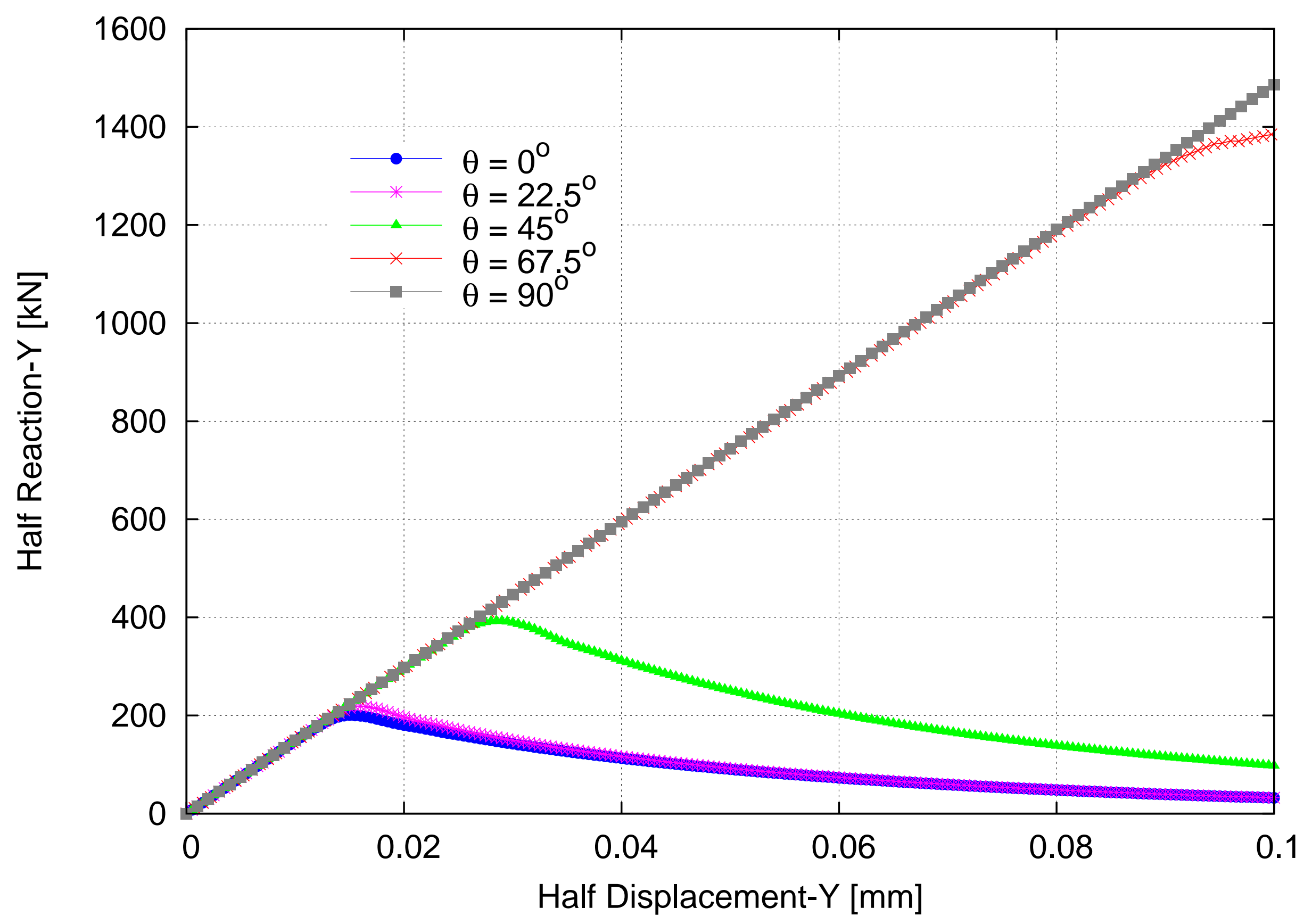




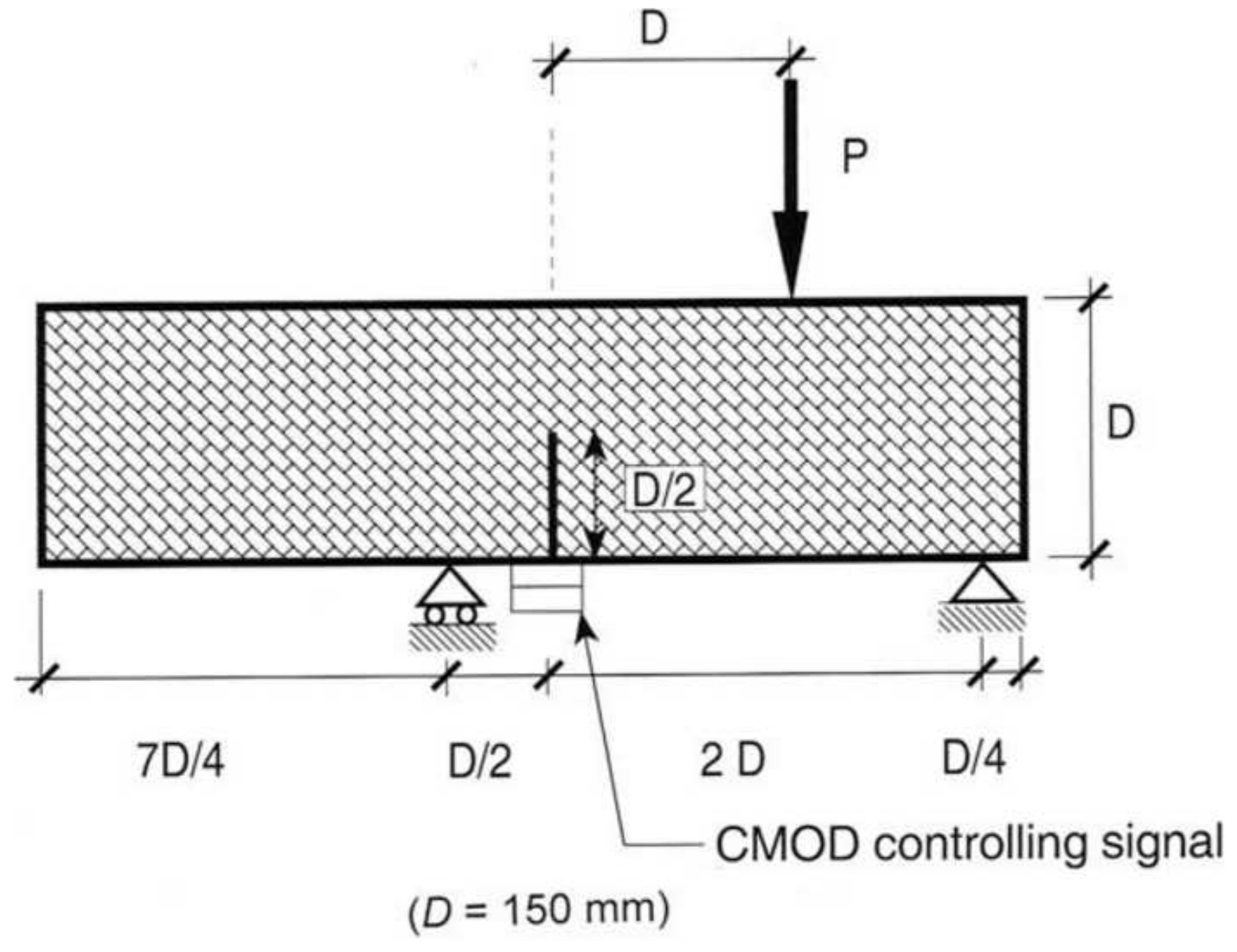

$(D=150 \mathrm{~mm})$ 


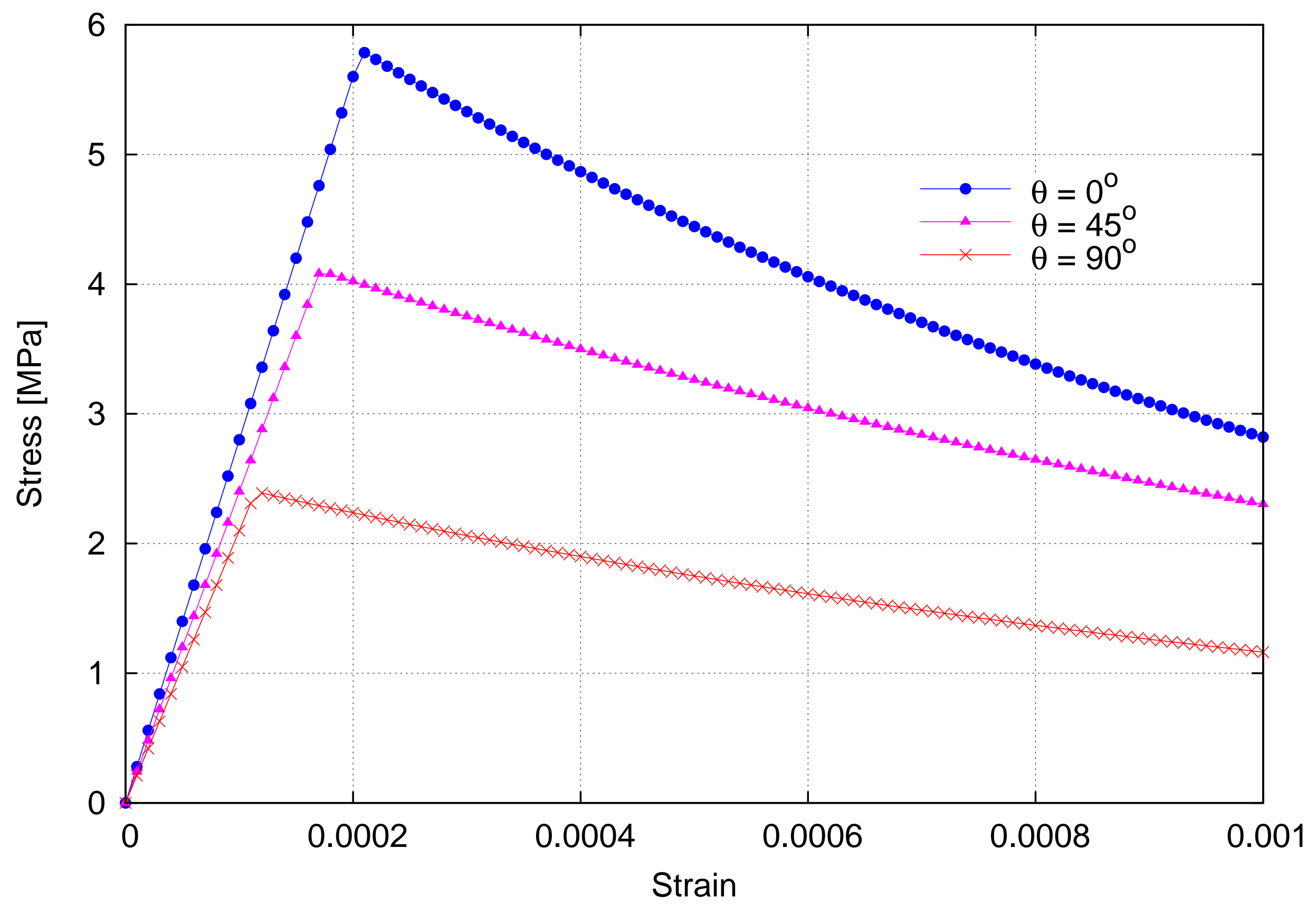


Figure 12
Click here to download high resolution image

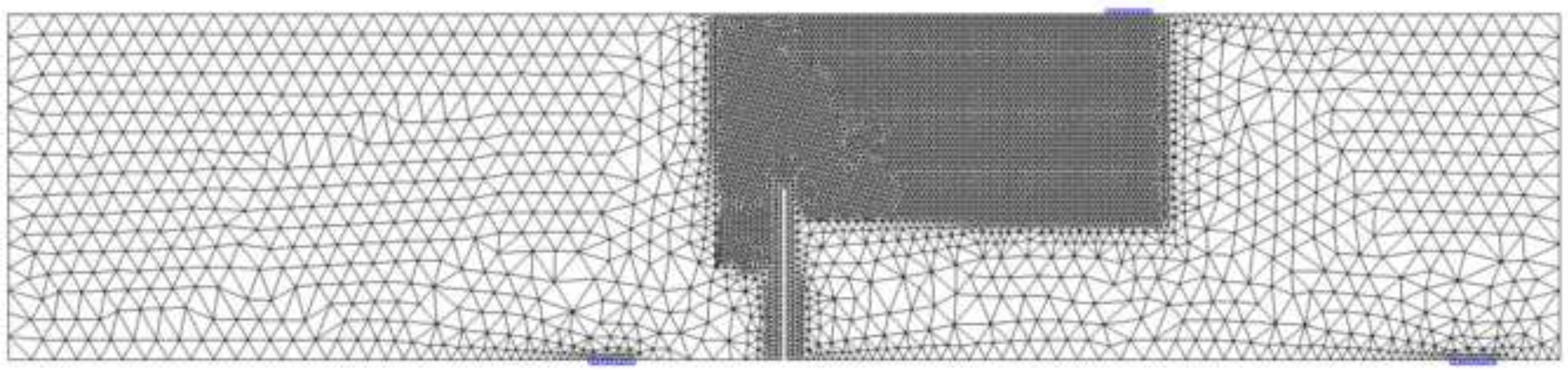

y. 
Figure 13

Click here to download high resolution image
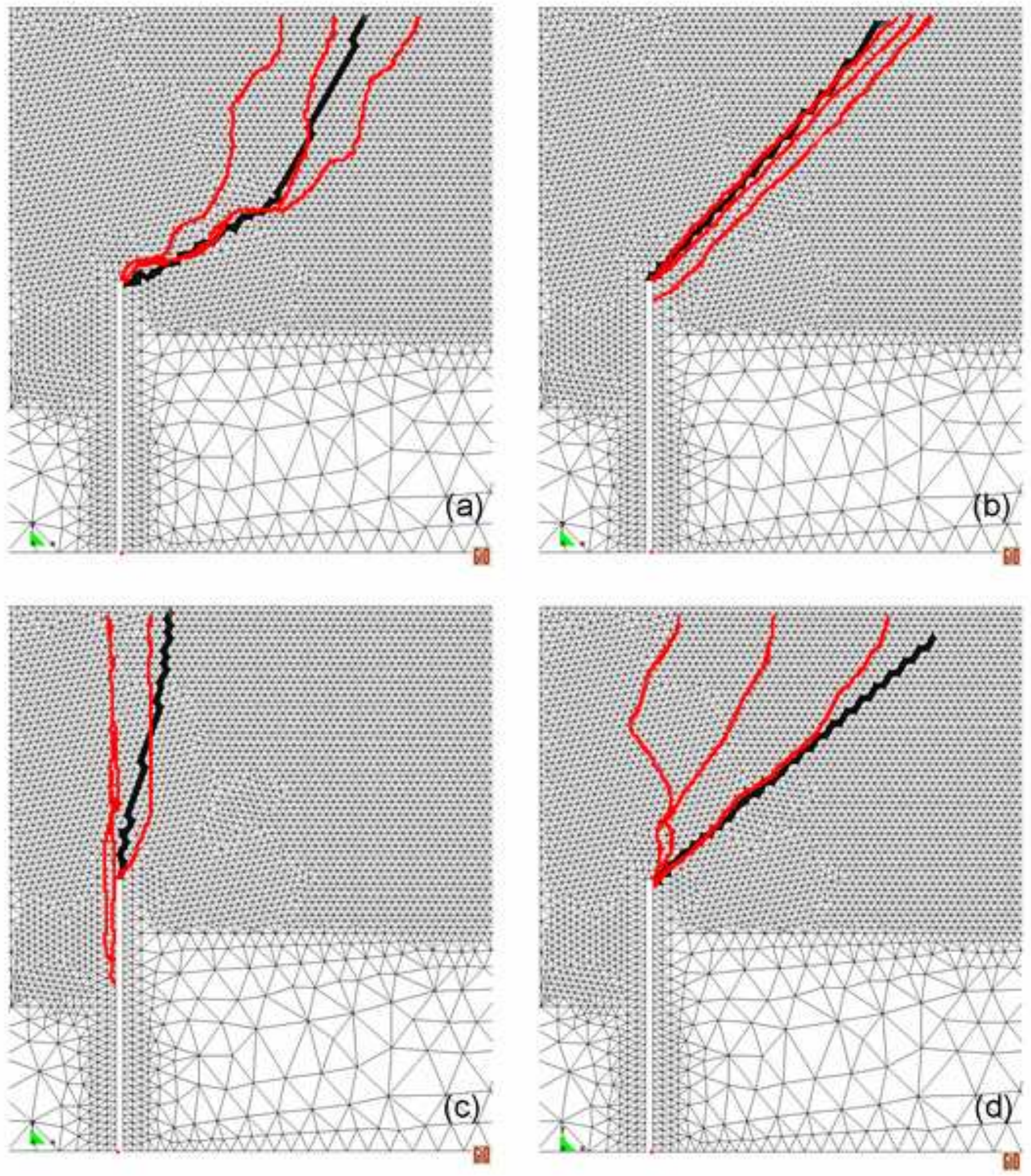
a) $\theta=0^{\circ}$

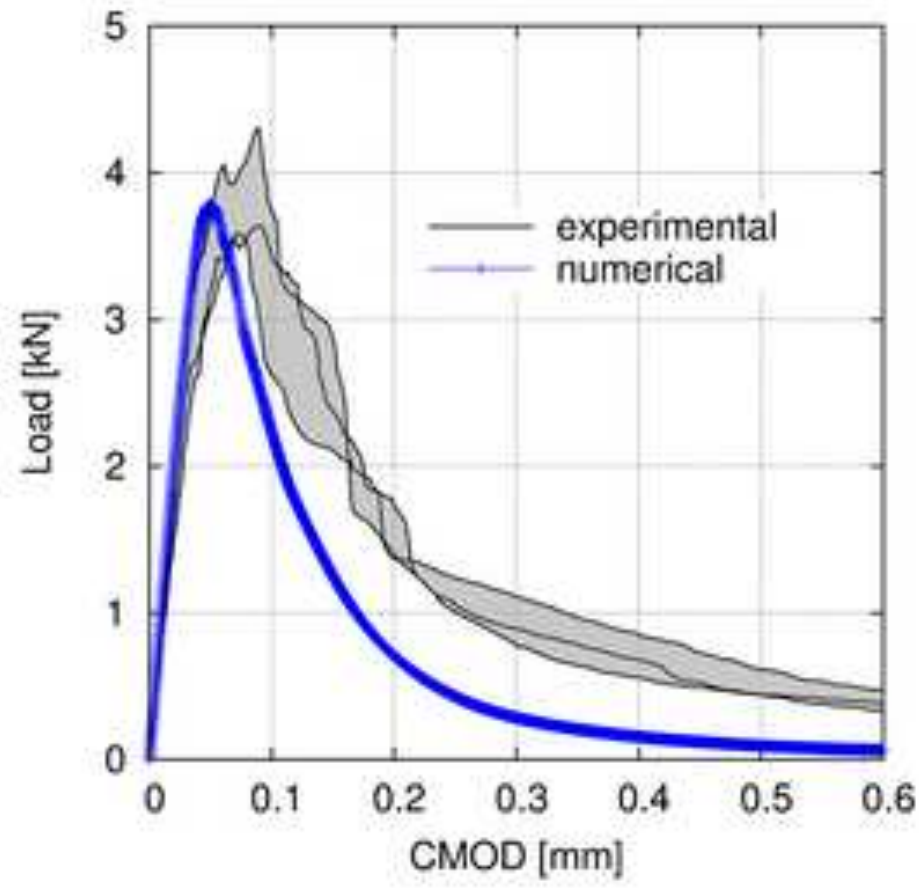

c) $\theta=90^{\circ}$

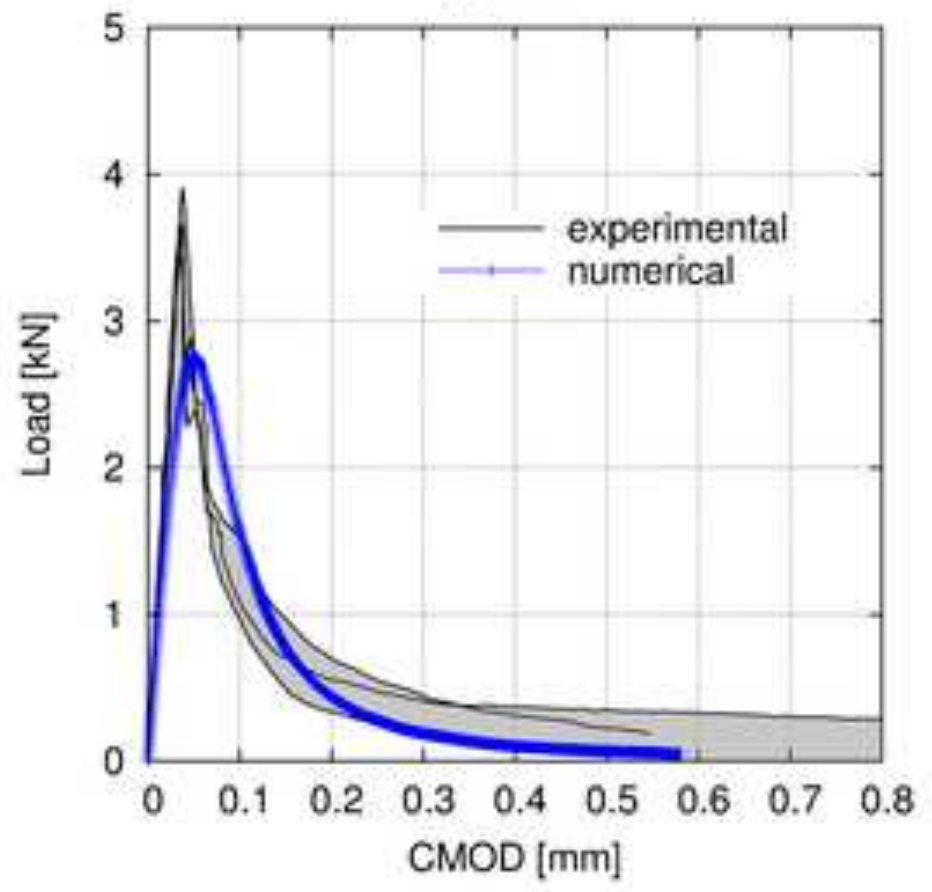

b) $\theta=45^{\circ}$

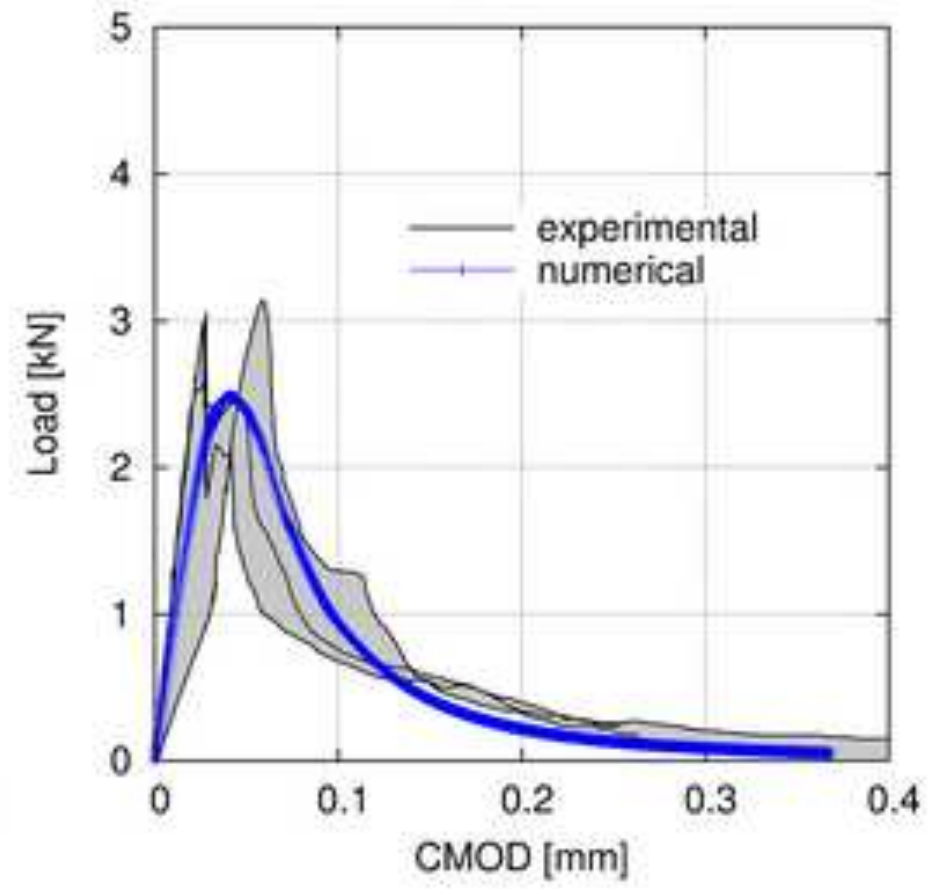

d) $\theta=-45^{\circ}$

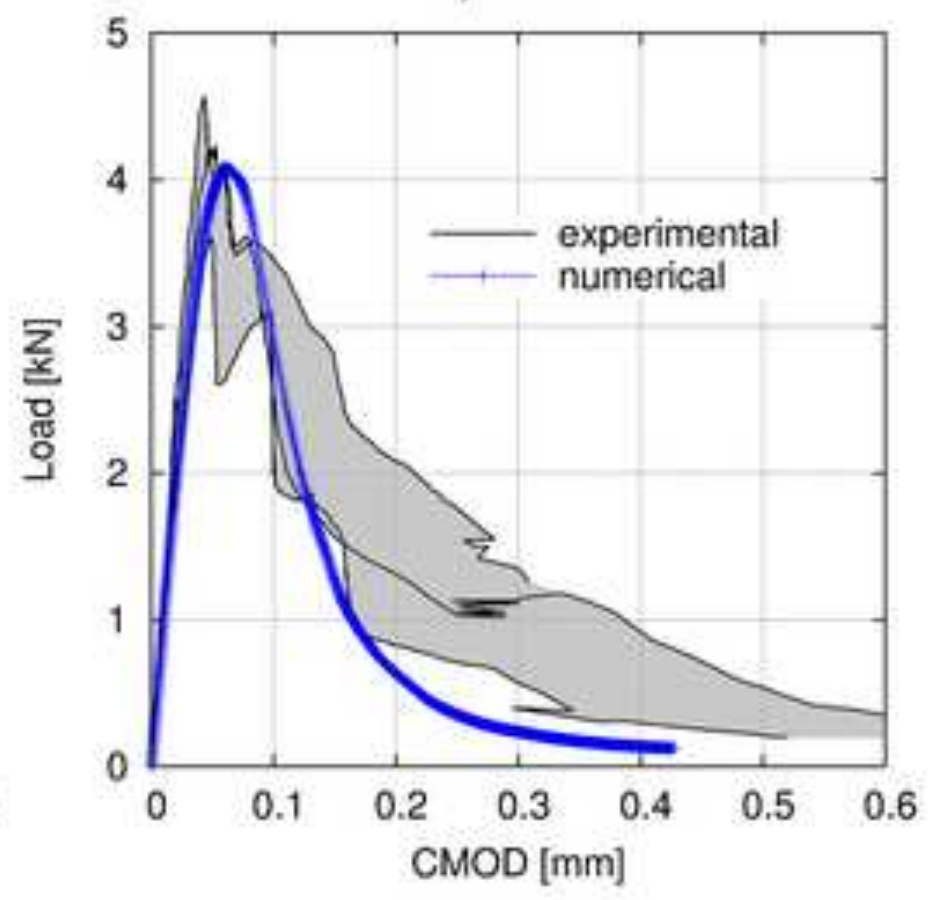

